University of Louisville

ThinkIR: The University of Louisville's Institutional Repository

Electronic Theses and Dissertations

$12-2009$

\title{
Anticipatory grief in the context of dementia caregiving.
}

Caitlin Holley

University of Louisville

Follow this and additional works at: https://ir.library.louisville.edu/etd

\section{Recommended Citation}

Holley, Caitlin, "Anticipatory grief in the context of dementia caregiving." (2009). Electronic Theses and Dissertations. Paper 625.

https://doi.org/10.18297/etd/625

This Doctoral Dissertation is brought to you for free and open access by ThinkIR: The University of Louisville's Institutional Repository. It has been accepted for inclusion in Electronic Theses and Dissertations by an authorized administrator of ThinkIR: The University of Louisville's Institutional Repository. This title appears here courtesy of the author, who has retained all other copyrights. For more information, please contact thinkir@louisville.edu. 


\title{
ANTICIPATORY GRIEF IN THE CONTEXT OF DEMENTIA CAREGIVING
}

\author{
By \\ Caitlin Holley \\ University of Louisville

\begin{abstract}
A Dissertation
Submitted to the Faculty of the Graduate School of the University of Louisville In Partial Fulfillment of the Requirements
\end{abstract}

For the Degree of

\author{
Doctor of Philosophy \\ Department of Psychological and Brain Sciences \\ University of Louisville \\ Louisville, Kentucky
}

December, 2009 
Copyright 2009 by Caitlin Holley

All rights reserved 


\title{
ANTICIPATORY GRIEF IN THE CONTEXT OF DEMENTIA CAREGIVING
}

\author{
By
}

Caitlin Killelea Holley

B.A., Nazareth College, 2003

M.A., University of Louisville, 2006

A Dissertation Approved on

June 19, 2008

By the following Dissertation Committee:

Dissertation Director 


\section{DEDICATION}

This dissertation is dedicated to my grandparents, Wesley and Patty McEntarfer. It was their endless devotion to one another that served as my inspiration, and reminded me of the importance of this work during times when I lost sight of the big picture. 


\section{ACKNOWLEDGEMENTS}

I would like to express my gratitude Dr. Benjamin Mast whose exceptional mentoring brought out the best in me as a graduate student. His constant guidance and encouragement gave me confidence and strength through every day of my graduate

career. Many thanks also to the members of my dissertation committee for their time and valuable comments regarding this project. I would also like to thank the members or Dr. Mast's lab for their friendship and support, and for always being able to put a smile on my face. Finally, I could not have succeeded without the love and support of my family. Many thanks to my parents, Michael and Deirdre McEntarfer for giving me all the opportunities to succeed in life, and to Heather, for always believing in her little sister.

Above all I owe a debt to my husband, Chris, for his endless patience and encouragement, and for being a best friend through it all. 


\begin{abstract}
ANTICIPATORY GRIEF IN THE CONTEXT OF DEMENTIA CAREGIVING

Caitlin Holley, M.A.

June 19,2008
\end{abstract}

The current study investigated the nature of anticipatory grief in a sample of dementia caregivers, and examined the relationship between anticipatory grief and caregiver burden. Anticipatory grief can be described as one's reaction to the impending death of a loved one, in addition to responses to other previously endured, ongoing, and anticipated losses. Interest in anticipatory grief has been inconsistent, and has typically focused on terminal diseases such as cancer. However, the issues involved in anticipatory grief are unique in the context of dementia due to the progressive deterioration of both cognitive and physical abilities. A total of 80 informal caregivers of individuals with dementia completed interviews and questionnaires assessing his or her experience of grief, physical and mental health, aspects of the caregiving situation, and the severity of patient impairment. Results reveal that anticipatory grief is strongly related to burden and its correlates, including depression, well-being, social support, and behavior problems in the care recipient. Anticipatory grief is shown to be a significant and independent predictor of caregiver burden in this sample, beyond the effects of known predictors such as background characteristics, primary stressors, and depressive symptoms. The current results suggest that grief may be an important yet understudied aspect of the caregiving 
experience. The nature of anticipatory grief in dementia caregivers is described, and recommendations for future research directions, including longitudinal examination of anticipatory grief, are provided. 


\section{TABLE OF CONTENTS}

PAGE

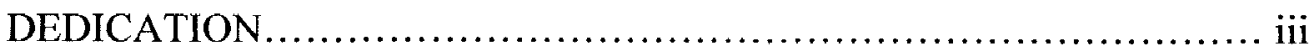

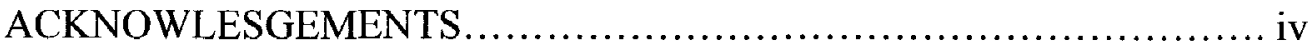

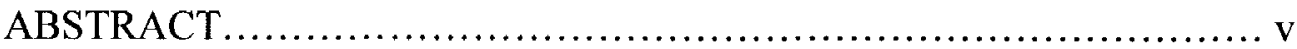

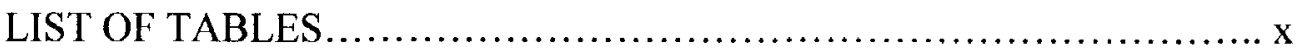

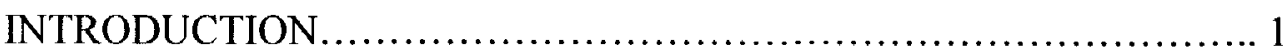

Historical Perspective on Anticipatory Grief........................ 2

Therese Rando's Multidimensional Model of Anticipatory Grief.... 7

Perspectives.......................................... 7

Time Focus................................................ 8

Influencing Variables.................................... 8

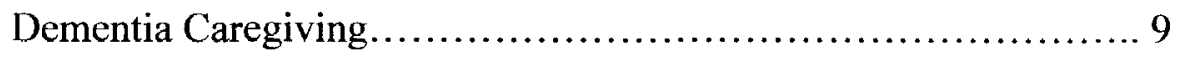

Anticipatory Grief in Dementia Caregiving...................... 14

Research Questions and Hypotheses................................. 19

METHODS............................................................... 22

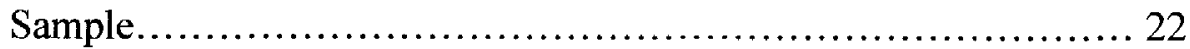

Measures...................................................... 22

Background Variables................................. 22

Care Recipient Variables................................... 23

Caregiver Variables.......................................... 24

Caregiver Anticipatory Grief............................ 28 
Procedures............................................................. 29

Statistical Power and Sample Size.............................. 30

Data Analysis..................................................... 31

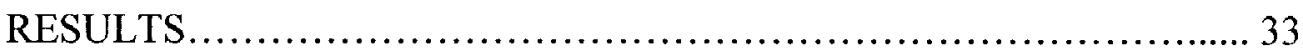

Demographics of the Sample.................................... 33

Hypothesis 1 Analysis........................................... 35

Hypothesis 2 Analysis........................................ 37

Hypothesis 3 Analysis......................................... 38

Hypothesis 4 Analysis......................................... 42

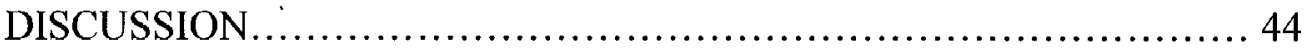

Study Question One .......................................... 44

Study Question Two.............................................. 46

Study Question Three.......................................... 49

Study Question Four........................................ 51

What does this study reveal about the nature of $A G$ in dementia

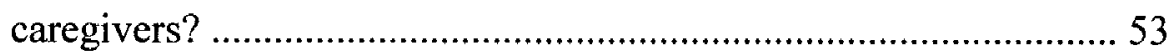

Is $\mathrm{AG}$ a missing component in models of caregiver burden? ........ 54

How can we differentiate AG from other caregiver outcomes? ...... 56

Limitations and Future Directions............................... 58

Implications.................................................... 62

REFERENCES................................................... 65

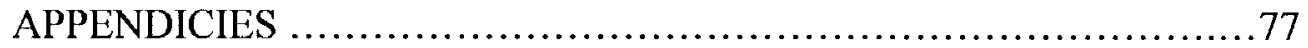

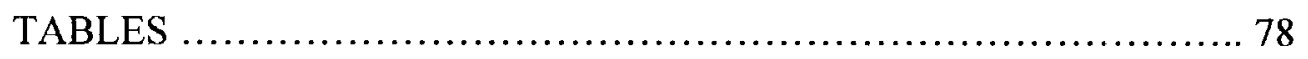




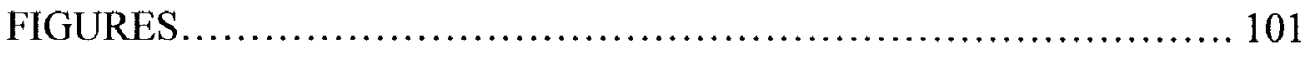

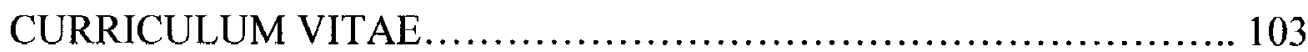




\section{LIST OF TABLES}

TABLE

PAGE

1 Recruitment Sources for Study Participants

2 Characteristics of Caregivers and Care recipients............. 80

3 Characteristics of the caregiving situation.................... 81

4 Descriptive Statistics for Key Study Variables............... 82

5 Bivariate correlations among demographics and measures of $\mathrm{AG}$ and caregiver burden............................. 83

6 Mean Anticipatory Grief Scores in Recent Studies............ 84

7 Bivariate Correlations between measures of $\mathrm{AG}$ and correlates of burden....................................... 85

8 Bivariate Correlations between AG and characteristics of disease severity ....................................... 86

9 Bivariate correlations between $\mathrm{AG}$ and RMBPC subscales.... 87

10 Mean levels of Anticipatory Grief by FAST stage............. 88

11 Analysis of Variance examining mean differences in grief scores (MM-CGI) by disease stage (FAST) ........... 89

12 Analysis of Variance examining mean differences in grief scores (AGS) by disease stage (FAST)............... 90

13 Hierarchical Linear Regression MM-CGI as measure of $\mathrm{AG}$ and $\mathrm{ZBI}$ as measure of caregiver burden

14 Hierarchical Linear Regression MM-CGI as measure of AG and Montgomery Burden Inventory as measure of caregiver burden. 
15 Hierarchical Linear Regression AGS as measure of AG and ZBI as measure of caregiver burden..................... 93

16 Hierarchical Linear Regression AGS as measure of AG and Montgomery Burden Inventory as measure of caregiver burden

17 Hierarchical Linear Regression including depression; MM-CGI as measure of $A G$ and $\mathrm{ZBI}$ as measure of caregiver burden.

18 Hierarchical Linear Regression including depression; MM-CGI as measure of AG and Montgomery Burden Inventory as measure of caregiver burden. 96

19 Hierarchical Linear Regression including depression; AGS as measure of $A G$ and $\mathrm{ZBI}$ as measure of caregiver burden.

20 Hierarchical Linear Regression including depression; AGS as measure of AG and Montgomery Burden Inventory as measure of caregiver burden 98

21 Bivariate Correlations between AG and relationship quality ratings

22 Bivariate Correlations among subscales of $A G$ and relationship quality..... 100 


\section{INTRODUCTION}

Receiving a diagnosis of a terminal disease triggers a variety of important reactions in the dying person and his or her family. The period of time between receiving a terminal diagnosis and death is often a time filled with sorrow, anxiety, uncertainty, and fear. There exists a great body of literature about grief responses to death, however there has been relatively little work focused on the grief work that occurs prior to death. The psychological experience occurring from the point of recognition and acceptance of the impending death until the time of death is called anticipatory grief (AG). Rando (1986) defines $\mathrm{AG}$ as "the phenomenon encompassing the processes of mourning, coping, interaction, planning, and psychosocial reorganization that are stimulated and begun in part in response to the awareness of the impending loss of a loved one (death) and in the recognition of associated losses in the past, present, and future" (pg 24). Although there was once great empirical interest in $A G$, very little research has been devoted to the topic in recent years despite its clear relevance to the terminally ill and their loved ones.

The purpose of this study was to advance our current understanding of AG by examining it in a distinct sample of grieving individuals. Family caregivers of individuals with dementia experience a particularly tragic variant of $A G$, due to the decline in both cognitive and physical abilities of their loved ones. The chain of events involving cognitive decline, and often a "social death" (when socially relevant attributes of the person are gone) that precedes physical decline and death in dementia, has been 
referred to as a series of "mini-deaths" (Marwit \& Meuser, 2005). During the progression of dementia family caregivers are confronted with losses of a variety of different aspects of the person they know, such as the loss of meaningful communication, emotional closeness, and aspects of his of her personality. These losses are known to prompt the experience of grief prior to death in some individuals (Meuser \& Marwit, 2001; Marwit \& Meuser 2002; Adams \& Sanders, 2004). This study examined anticipatory grief in a sample of informal dementia caregivers with the following aims: 1) to investigate the nature of $\mathrm{AG}$ in dementia caregivers and examine correlates of caregiver grief throughout the disease progression, and 2) to investigate the relationship between $A G$ and caregiver burden, and examine whether $A G$ contributes to our understanding of burden. It is proposed that $\mathrm{AG}$ is a key feature of the complex caregiving experience.

\section{Historical Perspective on Anticipatory Grief}

The concept of AG was first introduced by Erich Lindemann, who studied reactions to the loss of a close family member and laid the groundwork for what is considered a "normal" grief reaction today (1944). He described an "anticipatory grief" reaction of a wife whose husband returned from war to find she no longer loved him, by attributing her detachment to grief-work that had been completed in response to the threat of losing her husband. Lindemann's work was groundbreaking in its time, and the concept of AG was widely endorsed by clinicians and researchers working with terminally ill patients. Importantly, much of the empirical study of AG reflects the way Lindemann conceptualized it, which was rooted in classic psychoanalytic theory. In the classic psychoanalytic model of bereavement, it was believed that the major task of grief 
was to gradually detach oneself psychologically from the deceased, through characteristic stages of grief-work, and that one's ability to do so determined the duration of the grief reaction (Freud, 1917/1959).

Other theorists have proposed similar models of bereavement (e.g. Kubler-Ross, 1969; Horowitz, 1976), and as a result these stage models have become entrenched among those working with the bereaved (Wortman \& Silver, 1990). The prevailing theories propose that grief involves a progression through a series of stages which lead to decathexis from the deceased, allowing the bereaved to reinvest their emotional energy elsewhere. "Grief work" is identified as a central mechanism in the process of adjusting to bereavement, and a failure to do this work results in maladjustment. When these psychoanalytic theories of loss and grief are applied to the concept, AG is generally assumed to be the commencement of the grieving process, and thus on the same trajectory as conventional grief. A corollary of this assumption is that the more AG that occurs, the more grief work that is accomplished when the death comes, leading to better outcomes during bereavement (Fulton \& Gottesman, 1980).

Investigations of AG have been guided by these theories of grief, which have contributed to conceptual confusion regarding the true nature of AG. Specifically, AG has been oversimplified and considered to be conventional grief for the ill person begun prior to the death. However, this conceptualization fails to appreciate the other previously endured, ongoing, and anticipated losses inherent in a terminal situation. Moreover, AG has been confused with the concept of forewarning of the impending death (i.e. being informed of a terminal diagnosis), which is problematic because forewarning may be necessary but is not sufficient for AG to occur. In other words, $\mathrm{AG}$ does not necessarily 
occur because one acknowledges that a loss is imminent, but rather it is an active psychosocial process that is undertaken by the mourner (Rando, 1986).

Research on AG can be classified into two groups: early studies observed the reactions of parents of terminally ill children, while a second paradigm examined the effects of $A G$ on adjustment in spouses of terminally ill patients. The first group of $A G$ studies, conducted during the 1950s and 1960s, focused on interviews and/or observations of parents of children with cancer and yielded relatively consistent results (Binger, Albin, Feuerstein, Kushner, Zoger, \& Mikkelsen, 1969; Bozeman, Orbach, \& Sutherland, 1955; Richmond \& Waisman, 1955; Natterson \& Knudson, 1960; Chodoff, Friedman \& Hamburg, 1964). Most authors concluded that AG reactions occurred in most parents of terminally ill children, and that the reactions followed phases characteristic of conventional grief reactions. Most parents experienced a period of denial of the diagnosis, then feelings of anger and guilt as they began to reach acceptance, and finally some level of emotional withdrawal from the child in preparation for the death.

Although these studies conveyed important information regarding the reactions of parents to a terminal diagnosis in their children, they are severely limited in many ways. Typically, little effort was made to clearly define or operationalize key variables, notably AG. As a result, there is very little uniformity in the measurement and conceptualization of AG, making it difficult to identify its presence. Similarly, regarding bereavementrelated adjustment, variables such as depression, anxiety, atypical grief responses, and disturbances in functioning were rarely defined. This lack of clarity makes it difficult for readers to interpret the results and make comparisons across studies. The lack of 
definition and clear measurement of the variables does not lend itself to statistical analyses. As such, no attempts were made to examine correlations between AG reactions and psychological adjustment variables.

Despite these limitations, these early reports led scientists to begin to consider the psychological value of the AG construct. Beginning in the 1970s research focused on spouses of the terminally ill, and sought to determine whether AG influences postmortem grief. Typically, researchers examined differences in the length and intensity of grief reactions between widows and widowers whose spouses died suddenly compared to those whose spouses died after a prolonged illness (who presumably had forewarning of the impending death and thus the opportunity to experience AG). Although much evidence points to the benefits of forewarning on post-death grief (Ball, 1976; Doka, 1984; Glick, Weiss, \& Parkes,1974; Lundin, 1984; O’Bryant, 1990; Parkes, 1975), some studies suggest that having such forewarning has no effect (Gerber, 1975; Hill, Thompson, \& Gallagher,1988; Parkes, 1964; Sanders, 1982), while others point to the negative effects on bereavement-related adjustment (Clayton, Halikas, \& Maurice,1971; Clayton, Halikas, Maurice \& Robins, 1973).

There are a number of explanations for the discrepant findings regarding the costs and benefits of AG. Most importantly, there is the conceptual problem of equating the presence of a terminal illness with the experience of AG. Instead of operationally defining and measuring $\mathrm{AG}$, most of the studies cited above assumed that $\mathrm{AG}$ was present whenever a person had received a terminal diagnosis, and therefore studies examining the effects of forewarning of loss were labeled as studies of AG. Further, while $A G$ was assumed to be present if there was forewarning of the death, the 
operational definition of forewarning is unclear in that "sudden" and "anticipated" deaths are inconsistently defined. For example, although Sanders (1982) examined the effects of illnesses shorter and longer than 6-months duration, Parkes (1975) defined forewarning of the death as two weeks or more, and Ball (1976) defined forewarning as six or more days from the onset of symptoms. Beyond the problem of equating forewarning of death with $A G$, it is difficult to make comparisons across studies with forewarning so inconsistently defined.

With regards to measurement, outcome variables of bereavement-related adjustment were inconsistently defined and measured. While some studies measured outcome by means of frequency of medical consultations during bereavement (Parkes, 1964), others used self-report of health (Gerber, 1975), depressive symptoms (Clayton et al., 1971, 1973), or grief symptoms (Ball, 1976). Overall, methodological differences and problems in these studies limit the comparability, and raise compelling questions about the conclusions that are reached.

As a result of the misconceptions about the phenomenon of $A G$, investigations have resulted in these mixed conclusions regarding its nature and utility. The value of AG in terms of adjustment during the terminal period and after the death is not well understood. However, prior to addressing these issues, there are important aspects of the experience of $A G$ that need to be better understood. There is no clear understanding of the unique experience that one goes through when he or she comes to accept the meaning and reality of a terminal diagnosis and begins to grieve. 
Therese Rando's Multidimensional Model of Anticipatory Grief

In an attempt to clarify the picture, Rando (1986) has proposed a

multidimensional model of $\mathrm{AG}$ that broadens its conceptualization and can be useful in understanding how the experience varies among different affected people and with different diseases. Rando asserts that $\mathrm{AG}$ is multidimensional, occurring across two perspectives (experienced by the dying individual and their loved ones), three time foci (past, present and future), and is influenced by three classes of variables (psychological, social, and physiological) (Rando, 1986).

PERSPECTIVES: AG from the perspective of the ill person consists of confronting the fact that their life is now limited and grieving for the total extent of their self, their world, and everyone and everything in it. Although both perspectives are important and psychologically complex, AG is more frequently studied from the perspective of family members and other loved ones. Loved ones of the dying individual may experience a progressively deeper awareness of the seriousness of the illness and its implications as time passes and losses accumulate. In the context of dementia, changes in personality and a reduced ability to care for oneself may be perceived as losses by family members. This can activate emotional reactions such as sadness and mourning and cognitive reactions such as planning for the future and thinking about the death. The family must also cope with processes related to interactions with the dying person, which can involve balancing providing care and directing energy toward their loved one on the one hand, with resolution of the relationship and beginning to let go on the other. These interactions are particularly difficult in the context of dementia, as meaningful communication becomes increasingly difficult as the disease progresses. 
TIME FOCUS: Although the term AG may imply that it is solely a future loss that is being mourned, Rando's model posits that grief is experienced for past, present and future losses. During the course of a terminal illness, many losses have already occurred which might be mourned. For example, a husband caring for his wife in an advanced stage of dementia may grieve for the lost intimacy and communication he no longer has with her. Losses are also ongoing, and the ill person and family may also grieve for these in the present. The husband just mentioned may grieve for the loss of his own freedom as his life is consumed by caregiving tasks. Losses that are yet to come may also be mourned, including but not limited to the death of the ill person. For example, the loss of mobility and the ability to care for oneself that may occur prior to death may be grieved for in advance.

INFLUENCING VARIABLES: According to this model AG is an ongoing process that fluctuates with the mourner's acceptance of the death, and changes as multiple losses accumulate. It is an individualized experience, influenced by psychological, social, and physiological factors. Within the context of dementia caregiving, important psychological factors are the mental health and personal characteristics of the caregiver, and the nature of the relationship being lost. Unique fears related to dementia and the caregiver's perceptions of the syndrome may also influence his or her experience of grief. Important social factors include the family's response to the illness, and general socioeconomic and environmental factors such as social support, socio-cultural background, and financial resources of the grieving family. Physiological factors, such as the griever's own physical health, can also influence the experience of AG (Rando, 1986, 2000). 
$\mathrm{AG}$ is a very difficult process, exacerbated by the fact that we lack norms and expectations for how to act when a loved one is dying. This process may be even more ambiguous in dementia, as family members often have difficulty viewing dementia as a terminal illness (Sachs, Shega, \& Cox-Hayley, 2004). Family members of the dying must find ways to support the dying person and live as fully as possible with them until their death, all with the knowledge that they will eventually have to detach and learn to live without them. Rando's model can be useful in advancing our understanding of the unique impact of $A G$ on different populations, such as caregivers of individuals with dementia. Within this context, there is a need to deepen our understanding of the experience of AG and its affect on those providing care for their loved ones with dementia.

\section{Dementia Caregiving}

Each year approximately 350,000 individuals in the United States learn that a parent, spouse, sibling, or other loved one has been diagnosed with Alzheimer's disease or other dementia (Gorina, Hoyert, Lentzner, \& Goulding, 2006), leaving many with a sense of dread, uncertainty, fear, and shame. Care for individuals with dementia is usually provided by informal helpers such as adult children and spouses (Stone, Cafferata, \& Sangl, 1987). Being a care provider is a stressful experience that has measurable physical and mental health consequences, including higher rates of depression and infectious diseases, and compromised immune functioning (Haley, West, Wadley, Ford, et al., 1995; Haley, 1997; Kiecolt-Glaser, Dura, Speicher, Trask, \& Glaser, 1991; Schultz, O'Brien, Bookwala, Fleissner, 1995). Informal caregivers are more likely to report that their health is fair or poor when compared to non-caregivers (Schulz, et al., 
1995), and are less likely to engage in health-promoting and self-care behaviors (KeicoltGlaser et al., 1991). Depressive symptoms are twice as common among caregivers than non-caregivers, and some studies suggest that nearly half of dementia caregivers meet diagnostic criteria for clinical depression (Baumgarten, Battista, Infante-Rivard, Hanley, Becker, Gauthier, 1992; Gallagher, Rose, Rivera, Lovett, \& Thompson, 1989).

A major focus of the existing caregiving literature has been on the demands of caregiving and the corresponding distress that is produced. This burden is typically defined as "the physical, psychological or emotional, social, and financial problems that can be experienced by family members caring for impaired older adults" (George \& Gwyther, 1986, p. 253). Objective burden reflects the events and activities associated with negative caregiving experiences, and practical consequences of physical and behavioral changes of the care recipient. Objective burden is often distinguished from subjective burden, which is the emotional reactions of the caregiver, such as frustration, worry, and anxiety (Montgomery, Gonyea, \& Hooyman, 1985; Zarit, Reever, \& BachPeterson, 1980).

Although most caregivers likely experience high levels of stress, they vary greatly in their ability to cope with this stress and its impact on their lives and health. The individual variations in how people respond to stressful encounters has been viewed within the theoretical framework of the stress appraisal model (Lazarus \& Folkman, 1984). This contextual model emphasizes the interaction between individual (withinperson) factors and environmental factors to produce distress or satisfaction. Reactions are thought to be determined not only by the presence of an objective stressor, but by how the problem is appraised and how well the person is able to cope. When a stressor is 
appraised it is assessed for its level of threat, and compared to the person's ability to cope with that threat. It is the appraisal of the situation as stressful and burdensome that leads to subjective distress (Haley, Levine, Brown, \& Bartolucci, 1987). In other words it is the interaction between individuals and their environment that results in stress and burden.

In applying the stress model to dementia caregiving, a stress-process model has been used to identify factors that predict and influence caregiver burden and distress (Aneshensel, Pearlin, Mullan, Zarit, \& Whitlatch, 1995; Pearlin, Mullan, Semple, \& Skaff, 1990). In this model multiple aspects of caregiver stress are specified, which are influenced by a variety of background and contextual characteristics of the caregiver and the care recipient. Primary stressors arise directly from the caregiving situation and include behavior problems, physical and cognitive impairments of the care recipient, and the number of hours of care provision per week, all of which have consistently demonstrated associations with higher levels of burden and depression (Pinquart $\&$ Sorensen, 2005a). Secondary stressors are the result of difficulties outside the caregiving situation, such as family conflict or constrictions in one's social life. The background and context, including key characteristics of the caregiver and the nature of the relationship, are thought to influence stressors and outcomes, such as burden and depression (Pearlin et al., 1990). Finally, mediating conditions, such as social support, can influence the intensity of stressors and outcomes and can also have an impact on the relationship between stressors and outcomes. Figure 1 depicts an adapted version of Pearlin's stress-process model (1990), which has been extended by the addition of anticipatory grief. Not all elements of the original model were addressed in the current study; rather than be exhaustive an effort was made to represent each domain of the 
model. In all, background and contextual factors, stressors, and mediators interact to produce outcomes that lead to health and mental health consequences for the caregiver.

Although primary stressors such as a diagnosis of dementia and level of impairment consistently predict a small proportion of the variance in caregiver outcomes, how caregivers subjectively perceive their caregiving role and duties has been identified as an even stronger predictor of outcomes. Haley and colleagues (1987) demonstrated that after controlling for the objective severity of caregiving stressors, caregivers' appraisals of the subjective stressfulness of the situation and their coping responses was significantly related to higher levels of depression. The literature consistently supports claims that burden and depression are influenced by the frequency of behavior problems (Chappell \& Penning, 1996), and that these behavior problems are a more reliable predictor of burden and depression than the functional and cognitive impairments of the care recipient (Coen, Swanwick, O’Boyle, \& Coakley, 1997). Caregiver characteristics such as gender and health are consistent predictors of depression and burden such that female caregivers and those in poor overall health are more likely to experience negative psychological effects (Stuckey, Neundorfer, \& Smyth, 1996; Zanetti et al., 1997). The caregiving context is also important in predicting outcomes. Spousal caregivers are more vulnerable to high levels of burden and depression than non-spousal caregivers (Pruchno $\&$ Resch, 1989) whereas those with more social support are less susceptible to depressive symptoms (Coen, et al., 1997; Clyburn, Stones, Hadjistavropoulos, \& Tuokko, 2000).

Despite these consistent findings, the variables that have been studied so far explain relatively little of the variance in caregiver outcomes, and many inconclusive and contradictory results regarding caregiver outcomes have been reported (Pinquart \& 
Sorensen, 2005a). Conflicting results have been found regarding the effects of levels of functional impairment on outcomes (for example, Clyburn, et al., 2000). Moreover, the relationship between depression and burden is somewhat unclear, in that some, but not all of their variances are shared with each other, and they are likely influenced differently by different variables (Clyburn et al., 2000). In a critique of the literature on dementia caregiving, Raveis and colleagues (1990) called for a more comprehensive measure of the psychological impact of caregiving. Despite advances since that time, there continues to be very little consideration for variables like AG in attempting to explain caregiver burden and distress.

Caregiving is a complex psychological experience and it is possible that the absence of grief from conceptualizations of caregiver burden has delayed the development of a more accurate understanding of the full experience of caregivers. The emotional work of AG could contribute to a more complete picture of the caregiving experience when one considers the evidence that a number of grief-related losses are experienced by dementia caregivers. In a study of 94 caregivers, several common grief reactions were reported: loss of relationship (reported by $52 \%$ of their sample), changing communication with the care recipient (32\%), loss of freedom (31\%), and loss of future plans (30\%) (Farran, Keane-Hagerty, Salloway, Kupferer, 1991). Loos and Bowd (1997) surveyed dementia caregivers and in response to an open-ended question about what they had given up due to their role as a caregiver, four grief-related themes emerged: the loss of social and recreational activities, loss of control over life events, loss of well-being, and loss of occupation. Sanders and Corley (2003) also surveyed 253 dernentia caregivers about the losses suffered throughout their caregiving experience, and $68 \%$ of their sample 
reported grief, with the most common sources of grief being feelings of ambiguity about their relationship, loss of previously established roles and intimacy, and loss of control. Overall, there is evidence that the majority of dementia caregivers are experiencing grief for current and future losses, yet grief has not been considered within most conceptualizations of caregiver burden.

Anticipatory grief in dementia caregiving

A few studies have attempted to examine the grief of caregivers during the progression of dementia. Walker and Pomeroy (1997) were the first to explicitly examine the effects of $\mathrm{AG}$ on the functioning and adjustment of dementia caregivers. Structured interviews were conducted with 100 caregivers of persons with Alzheimer's disease (AD) and adjustment was measured in terms of subjective distress, life satisfaction, and health problems. The Stage of Grief Inventory (SGI) was designed by the researchers to measure the extent to which the participants expressed feelings characteristic of the following five stages of AG proposed by Teusink and Mahler (1984): denial, over-involvement, anger, guilt, and acceptance. The intensity of grief feelings was assessed by the Despair scale of the non-death version of the Grief Experience Inventory (GEI; Sanders, Maugler, \& Strong, 1985), which measures feelings of pessimism, hopelessness, worthlessness, and low self-esteem. Although the demands of caregiving (i.e. the length of time providing care, personal characteristics of the caregiver, and severity of symptoms) were significantly related to caregiver adjustment (accounting for $26 \%$ of the variance in subjective distress), feelings of grief were also very important (increasing the amount of explained variance to $40 \%$ ). In fact, intensity of grief was the most consistent and largest predictor of caregiver adjustment and health problems, and 
was also related to decreased life satisfaction. Stage of grief was also a good predictor of caregiver outcomes; caregivers in the anger and guilt stages experienced significantly higher levels of subjective distress. Based on these results the authors concluded that grief in caregivers over the progressive decline of a loved one with $\mathrm{AD}$ is an important predictor of current adjustment.

This study represents a noteworthy contribution to the literature in that it was the first to examine the impact of $\mathrm{AG}$ on the adjustment of $\mathrm{AD}$ caregivers. However, the GEI, which was used to measure intensity of grief reactions, is an instrument designed for the measurement of conventional grief, rather than AG. This is problematic because AG differs from conventional grief; AG includes the grief that is experienced for past, present, and future losses including but not limited to the future loss of the ill person. As such, the use of this measure may have assessed only a small portion of the AG that was experienced by the caregivers in this study. The use of empirically derived tools specifically designed for the measurement $A G$ is preferable.

Meuser and Marwit (2001) attempted to gain a fuller understanding of the AG of $\mathrm{AD}$ caregivers through a qualitative analysis of data obtained from focus groups held with spouse and adult-child caregivers of individuals with dementia (mostly AD) in mild, moderate, severe, and deceased stages. Through this method they sought to describe the key characteristics of caregiver grief at each stage of dementia, and to identify differences and similarities between spouse and adult-child caregivers. They also sought to explore the effects of AG on adjustment during bereavement. The Clinical Dementia Rating scale (CDR; Morris, 1993) was used to determine the disease stage of the care recipient, and these groups provided the basis for a descriptive model of grief over the course of 
dementia. The post-death groups of former caregivers provided the basis for descriptions of the impact of $\mathrm{AG}$ on subsequent adjustment. Eight focus groups were conducted: separate adult-child and spouse caregiver groups for each of the three CDR stages, and for the post-death groups.

Analyses of the transcribed focus group discussions revealed that adult children and spousal caregivers experienced different grief reactions at each stage of the disease. In CDR stage one (mild dementia), spousal caregivers focused on the loss of coupleoriented aspects of the relationship (e.g. shared hobbies or activities), whereas adult-child caregivers tended to express denial and avoidance of grief. In CDR stage two (moderate dementia) spouse caregivers continued to focus on the loss of intimacy and companionship, and expressed feelings of great sadness and compassion, whereas the reactions of adult-child caregivers were characterized by intense feelings of anger and frustration, and a focus on their personal losses, such as freedom. At stage three, the most advanced stage of the disease, spousal caregivers expressed feelings of uncertainty regarding how to proceed with life, a loss of the marital relationship, and anger and frustration with the "life-death limbo." During this stage, the anger of the adultchildren's grief was replaced by deep sadness in recognition of the absolute loss of their parent. For both spousal and adult-child caregivers in the post-death groups, there was an initial sense of relief from intense grief after the death, with many experiencing resurgence in grief after some time (Meuser \& Marwit, 2001).

This study represents the only systematic examination to date of grief across the course of dementia, including the bereavement period. By including caregivers providing care for individuals at all disease stages, the authors create a reasonable alternative to a 
longitudinal design. The results suggest that for adult-child caregivers grief may be curvilinear in nature with minimal grief experienced at stage 1 , intense grief at stage 2 , and moderate amounts of grief at stage 3 . In this group, when grief is most intense, anger and frustration appear to be the most prominent emotions, which gradually shift to sadness as the disease progresses. In contrast, the grief of spousal caregivers appears to increase linearly from stage one to three, with sadness being the predominant emotion during stages one and two, and then anger and frustration in stage 3 (Meuser \& Marwit, 2001). The results suggest the importance of studying AG in caregivers in a stagesensitive, caregiver-specific model.

In an attempt to do so, Adams and Sanders (2004) surveyed a sample of 99 informal caregivers of persons with $\mathrm{AD}$ from ages $28-89$ (mean age $=59.07$ years; $70 \%$ female). Each caregiver completed the Marwit-Meuser Caregiver Grief Inventory (MMCGI), the GDS, and responded to open-ended questions about whether or not they were grieving the loss of their loved one, and the greatest areas of loss as a result of the illness and their caregiving role. Results showed that while moderate levels of grief and depression were reported by those caring for people at all stages of the disease, those caring for people in the late stage of dementia reported significantly more symptoms of grief and depression than those in early or middle stages. In their sample, adult children and spouse caregivers did not differ significantly in the amount of grief or depression reported across the disease stages. Consistent with Meuser and Marwit's (2001) findings, responses to the open-ended questions varied by disease stage. Although those caring for people in the early stage of dementia focused on missing activities once shared with that person, those in the middle stage discussed losses related to the personal changes within 
the caregiver, such as loss of personal time and energy. Those with loved ones in the final stage mentioned losses related to the interpersonal relationship and how it had changed over the years.

This is the first study to utilize a standardized measure of caregiver grief. However, the relatively small sample size may have limited statistical power and the ability to detect a significant interaction. Specifically, the lack of significant interactions between the grief and depression reported by spousal $(n=35)$ and adult child $(n=50)$ caregivers across disease stage could be the result of insufficient power rather than an absence of a true effect. Despite this, this study contributed greatly to what is known about the grief experienced by caregivers across the various stages of dementia.

Caregivers of dementia victims represent a group that has been extensively studied with a relative disregard for their AG. The importance of understanding the experience of $\mathrm{AG}$ is great, and only recently has it been recognized in the professional literature as a definable phenomenon occurring in persons caring for those with dementia. The current study will build on the earlier work reviewed by using empirically supported instruments to investigate questions that have been previously studied in a qualitative fashion. It is proposed that consideration of caregiver AG can help to clarify the concept of caregiver burden by uncovering some of the emotional components of burden that may be triggered by perceived losses. Support of this idea comes from a longitudinal study of the bereavement outcomes of family caregivers (Shultz, Beach, Lind, Martire, Zdaniuk, Hirsch, et al., 2001). In their sample of 129 caregivers aged 66 to 96, Shultz and colleagues found that those reporting high levels of strain during their loved ones' illness experienced a decrease in depressive symptoms and an increase in healthy behaviors 
during bereavement as compared to non-caregivers and non-strained caregivers. They suggest that the caregivers reporting high levels of strain may have had the ability to grieve prior to the death and emotionally prepare for the death and the aftermath.

The current study has applied elements of Rando's (1986) model of AG to the examination of grief in a sample of dementia caregivers. Specifically, grief was measured in response to past, present, and future losses by means of instruments designed to assess such reactions (MM-CGI and AGS). In addition, influencing variables such as the quality of the relationship, caregiver physical and mental health, social support, and the behavior of the dying individual were measured. In the context of a stress-process model it is possible that grief is a secondary stressor which results from primary stressors such as cognitive decline, behavior problems, and the increasing need for physical assistance over time (See Figure 1). It could also be that AG is a unique caregiver outcome, experienced in response to physical and behavioral changes being perceived as losses. Many caregivers report that the emotional labor of caring for a loved one is much more demanding than the physical care tasks (Loos \& Bowd, 1997). This perception may be influenced by the experience of AG and likely influences their feelings of burden.

\section{Research Questions and Hypotheses}

Based on the literature reviewed, the current study addressed the following research questions:

1. What is the experience of AG like in dementia caregivers? In order to validate the construct of AG in a sample of dementia caregivers, we explored the relationship between $\mathrm{AG}$ and correlates of caregiver burden, including depression, well-being, 
physical health, and social support. A recent review highlights these variables as being strongly related to the provision of care to an older family member (Pinquart \& Sorensen, 2005a). It was hypothesized that higher levels of AG would be associated with more symptoms of depression, less positive well-being, and worse physical health. It was also hypothesized that more social support would be related to lower levels of $\mathrm{AG}$, based on consistent reports of more social support being related to lower levels of burden (Clyburn et al., 2000; Coen, et al., 1997).

2. Do characteristics of the disease severity influence AG? It was hypothesized that anticipatory grief would be related to the disease stage such that higher levels of grief will be observed in later stages of dementia. In addition, it was hypothesized that greater physical impairments and more severe behavioral problems will be associated with higher levels of AG.

3. What is the relationship between $A G$ and caregiver burden? Current conceptual models of caregiver burden consider physical, psychological, social, and financial sources of strain. However, grief is rarely considered in these models. It was hypothesized that $\mathrm{AG}$ would be a significant independent predictor of caregiver burden across disease stages. It was expected that AG would contribute to caregiver burden even after controlling for background characteristics of the caregiver, primary stressors including behavior problems of the care recipient, his or her impairments in ADLs and IADLs, and the number or hours of care provision per week, and the caregiver's level of depressive symptoms. 
4. How is AG influenced by characteristics of the relationship between the caregiver and the care recipient? Although this effect has not been studied extensively in the grief or caregiving literatures, it was explored in this study. It was expected that higher levels of closeness and satisfaction, and lower levels of conflict in the relationship would be related to higher levels of AG, based on findings that high levels of marital closeness and lower levels of conflict are related to more intense grief symptoms during bereavement (Carr, House, Kessler, Nesse, Sonnega, \& Wortman, 2000). 


\section{METHODS}

Sample

Participants comprised of 80 primary caregivers of persons with mild, moderate, or severe dementia. Caregivers were recruited from a variety of sources including advertisements, support groups, nursing homes, and contacts with community physicians in order to yield a heterogeneous sample. Eligibility for inclusion required that the caregiver be a family member or close friend of an adult with dementia, who at the time of participation in the study provided some level of care and support for that person. Data from one participant was excluded from the study because the care recipient had passed away prior to the caregiver's participation.

\section{Measures}

Background Variables

Sociodemographic information for caregivers and care recipients were collected through caregiver report, and included gender, age, racial/ethnic group, marital status, living arrangements, education level, employment information, household income, and caregiver's relationship to the care recipient. 


\section{Care-recipient variables}

Functional Assessment Staging of Alzheimer's disease (FAST)

The FAST (Reisberg, 1988) is a 16-item tool designed to allow professionals and caregivers to evaluate changes in functional performance and activities of daily living skills in individuals with Alzheimer's disease based on seven distinct stages. The FAST, which was used as an indicator of disease stage, has demonstrated inter-rater reliability with an interclass correlation coefficient of .87 , and concurrent validity through correlations with scales of cognitive and physical ability ranging from .60 to .79 (Sclan \& Reisberg, 1992). In the current sample, internal consistency was moderate (alpha $=.72)$.

\section{Index of Activities in Daily Living Scale}

The Index of Activities in Daily Living Scale (ADL; Katz, Ford, Mosckowitz, Jackson, \& Jaffe, 1963) was used to assess the level of assistance a care recipient needs to perform tasks such as bathing, dressing, eating and toileting. Inter-rater reliability has been reported at .95 (Kane \& Kane, 1981), and the scale has been correlated with mobility, house confinement, and measures of cognitive and functional abilities (Loewenstein \& Mogosky, 1999). Internal consistency for this scale in the current sample was high ( $\mathrm{r}=$ .89).

\section{Instrumental Activities of Daily Living Scale}

The Instrumental Activities of Daily Living Scale (Lawton \& Brody, 1969) assesses assistance a care recipient needs for higher-level tasks of self-care, such as using the telephone, preparing meals, and doing household chores. This scale has demonstrated 
high internal consistency (Loewenstein \& Mogosky, 1999) and been shown to correlate moderately with scales of physical self-maintenance and mental status (Lawton \& Brody, 1969). In the current sample, internal consistency was moderate (alpha $=.71$ ).

\section{Amount of Care Provided}

Caregivers were also asked to indicate the length of time (in months) they had been providing care for the care recipient, and the average number of hours of care provision per week, which has been shown to be a consistent correlate of caregiver burden (Pinquart \& Sorensen, 2005a).

\section{Caregiver Variables}

\section{Charlson Comorbidity Index}

Caregiver Health was measured using a self-report version of the Charlson Comorbidity Index (CMI; Charlson, Pompei, Ales, \& MacKenzie, 1987). The CMI is a weighted combination of chronic diseases originally created for use in predicting mortality. The CMI has been validated as a predictor of one-year survival in medical patients (Charlson et al., 1987) and ADL recovery in medical rehabilitation patients (Moore \& Lichtenberg, 1996).

\section{Self-Rated Health}

Perceived health status was measured using a single item: "In general, would you say your health is....(circle one) Excellent, Very Good, Good, Fair or Poor." This item has 
been linked with mortality and other health outcomes in the gerontology literature (Idler \& Benyamini, 1997)

\section{The Revised Memory and Behavior Problems Checklist}

The Revised Memory and Behavior Problems Checklist (RMBPC) is a 24-item caregiver report measure of observable behavioral problems in persons with dementia (Teri, Traux, Logsdon, Uomoto, Zarit, \& Vataliano, 1992). The scale provides a total score, and three subscale scores for patient problems (memory-related, depression, and disruptive behaviors) and parallel scores for caregiver reaction. The scale demonstrated good reliability in the current sample, with alphas of .84 for patient behavior and .90 for caregiver reaction. Validity has been demonstrated through associations with wellestablished measures of depression (Hamilton Depression Rating scale) for the depression subscale and cognitive impairment (MMSE) for the memory-related problems subscale (Teri et al., 1992).

\section{Interpersonal Support Evaluation List-Short Form}

A 6-item version of the Interpersonal Support Evaluation List (ISEL; Cohen, Mermelstein, Kamarck, \& Hoberman, 1985) was used to measure perceived social support. The full length ISEL was designed to measure four functions of perceived support: tangible (i.e., material assistance or instrumental support), belonging (i.e., identification with one's social network), self-esteem (i.e., from positive comparisons with others), and appraisal support (i.e., informational support), and has been shown to correlate moderately with other scales of social support (Coen et al., 1985). The 6-item 
version has been used in previous work with alpha $=0.73$ (Schulz \& Williamson, 1990), and had a cronbach's alpha of 0.69 in the current sample. All items were rated on a 4 point scale with definitely false, probably false, probably true, and definitely true as possible responses.

\section{Relationship Quality}

Perceived relationship quality with the care recipient was evaluated using the following questions: "Before his/her illness, how close was your relationship with your loved one?", "Before his/her illness, how much conflict was in your relationship with your loved one?", and "How satisfied are you with your current relationship with your loved one?". Responses were rated on a 7 point likert scale ranging from "not at all" to "extremely".

\section{Zarit Burden Interview Short Form}

The Zarit Burden Interview Short Form (Bedard, Molly, Squire, Lever, O’Donnell, 2001) is a shortened 12-item version of the original 22-item Zarit Burden Interview (Zarit, Orr, $\&$ Zarit, 1985). The scale examines burden associated with functional/behavioral impairments of the care recipient. The items possess content validity in that they reflect common areas of concern for caregivers, including health, finances, social functioning, and interpersonal relations. Internal consistency reliability has been demonstrated previously with a cronbach's alpha of .88 for this shortened version of the form. In the current sample, internal consistency was also high $($ alpha $=.88)$. The short form 
correlates highly with the original version $(r=.92-.97)$. A 5-point scale, ranging from never to nearly always present, is used.

\section{Montgomery Burden Inventory}

Montgomery, Gonyea, and Hooyman (1985) designed a measure of caregiver burden consisting of a 9-item inventory of objective burden (Cronbach's alpha $=.83$ ), which measures changes and disruptions as a result of the caregiving situation, and a 13-item inventory of subjective burden (Cronbach's alpha $=.83$ ), which measures attitudes and emotional responses of caregivers. The scale is rated on a 5-point likert scale, and the objective and subjective inventories are significantly correlated with one another $(r=.42$, $\mathrm{p}<.01$ ). The full scale, consisting of objective and subjective burden items, demonstrated good internal consistency in this sample (alpha $=.86)$.

\section{Geriatric Depression Scale}

The GDS is a 30-item self-report measure consisting of yes/no statements and is a wellestablished screening instrument for depressive symptoms in older adults (Brink, Yesavage, Lum, Heersema, Addey, \& Rose, 1982). The 15-item short form (Sheikh \& Yesavage, 1986) was used for this study, and demonstrated good internal consistency $(a l p h a=.83)$. The short form correlates highly with the full version (Sheikh \& Yesavage, 1986) and has also been used in caregiver research to assess depressive symptoms in younger adults (Adams \& Sanders, 2004). 


\section{Psychological Well-Being}

Ryff's six psychological well-being scales include assessments of six dimensions of wellness: autonomy, personal growth, positive relations with others, purpose in life, selfacceptance, and environmental mastery. An abbreviated version consisting of 3 items from each scale was used, which demonstrated moderately high internal consistency in this sample (alpha $=.79)$. Validity is demonstrated in associations with other prominent correlates of well-being, including happiness, life satisfaction, and depression (Ryff, Lee, Essex, \& Schmutte, 1994).

\section{Caregiver Anticipatory Grief}

\section{Marwit-Meuser Caregiver Grief Inventory}

The MM-CGI (Marwit \& Meuser, 2002) is a 50-item self report scale designed to measure grief responses of family caregivers of people with Alzheimer's disease. The scale is made up of three factors: personal sacrifice and burden, heartfelt sadness and longing, and worry and felt isolation, which sum to create a total grief score, with higher scores indicating greater levels of anticipatory grief. Validity of the scale has been demonstrated through correlations of each factor and the total score with the Anticipatory Grief Scale (Pearson r's .67 to .80). In the current sample the Cronbach's alpha score for the total scale was .96 , and ranged from .88 to .94 for the three subscale scores, indicating high internal consistency reliability for each factor and the total score. In this sample, the subscale scores correlate highly with one another (Pearson r's .69 to .79$)$ and very highly with the total score (Pearson r's .86 to .92). 
Anticipatory Grief Scale

The Anticipatory Grief Scale (AGS; Theut et al., 1991) is a scale designed for the assessment of grief in dementia caregivers. The 27 -items of this scale are responded to on a 5-point Likert scale and reflect feelings of anger, guilt, anxiety, irritability, sadness, feelings of loss, and decreased ability to function at usual tasks. The scale demonstrates good internal consistency in the current sample (alpha $=0.89$ ) and has been previously shown to correlate significantly with Hopkins Symptoms Checklist subscales of depression, anxiety, and hostility (Theut et. al., 1991).

\section{Procedures}

Persons responding to advertisements were provided with a description of the study over the telephone and invited to participate. Those who agreed to participate and who met the inclusion criteria had two options: 1) Either an appointment was scheduled with the participant to administer the study packet as an interview, or 2) the study packet was completed independently by the participant. In such cases, the study packet was mailed to participants along with instructions for how to complete each measure and a self-addressed, stamped envelope for return and the consent forms were explained to the participant in person or over the phone. Forty seven participants completed the study packet as an interview, and 33 participants completed the questionnaires independently. 
Statistical Power and Sample Size

Hypotheses 1 and 2:

Selected effect sizes from published studies concerning the relationship of grief with depression, well-being, health, and social support suggest medium to large effect sizes (Marwit \& Meuser, 2002; Walker \& Pomeroy, 1997). According to Adams and Sanders (2004) the effect size for the relationship between grief and dementia severity, as rated by the caregiver, is large. To obtain power of .80 , with two-tailed tests and an error rate of .05 , these analyses suggest a sample size of $\mathrm{N}=80$.

\begin{tabular}{|l|l|l|}
\hline & Effect Size & N needed \\
\hline $\begin{array}{l}\text { Depression } \\
\text { (Marwit \& Meuser, 2002) }\end{array}$ & $\mathrm{r}=.714$ & 12 \\
\hline $\begin{array}{l}\text { Well-being } \\
\text { (Marwit \& Meuser, 2002) }\end{array}$ & $\mathrm{r}=-.66$ & 15 \\
\hline $\begin{array}{l}\text { Health Problems } \\
\text { (Walker \& Pomeroy, 1997) }\end{array}$ & $\mathrm{r}=.496$ & 27 \\
\hline $\begin{array}{l}\text { Social Support } \\
\text { (Marwit \& Meuser, 2002) }\end{array}$ & $\mathrm{r}=-.36$ & 55 \\
\hline $\begin{array}{l}\text { Dementia Severity } \\
\text { (Adams \& Sanders, 2004) }\end{array}$ & $\mathrm{d}=.65$ & 78 \\
\hline
\end{tabular}

Hypothesis 3:

The relationship between grief and caregiver burden is understudied. To date, only one study has examined the direct relationship (Marwit \& Meuser, 2002), and that study found that the effect size is large $(r=.656)$. A G-power analysis suggests that a sample size of 15 should be sufficient to detect the effect, with power of .80 for a twotailed test.

It was hypothesized that $A G$ would be significantly related to caregiver burden while controlling for known predictors, and so a more conservative power analysis was conducted. The effect size for the relationship between AG and caregiver adjustment via 
regression analyses in which other predictors were considered (Walker \& Pomeroy, $1997)$ is medium $\left(f^{2}=.14\right)$. To achieve power of .80 for this relationship, 59 participants would be needed.

\section{Data Analysis}

Descriptive data analysis and data screening were carried out using SPSS 16.0. Several questions were examined in this study. The first research question addressed the relationship between $\mathrm{AG}$ and correlates of caregiver burden. Bivariate correlations were computed to examine the relationship between AG (MM-CGI, and AGS) and depression (GDS), well-being (Ryff's Psychological well-being scales), physical health (CMI and self-rated health), and social support (Interpersonal Support Evaluation List).

The second question addressed the relationship between disease severity and AG. Bivariate correlations were computed to examine the relationship between $A G$ and the various disease stages (FAST), behavior problems (RMBPC) and with levels of functioning in ADLs and IADLs. Mean levels of AG by FAST stage were computed and mean level differences were examined using Analysis of Variance (ANOVA).

The third question addressed the relationship between $A G$ and caregiver burden. The relationship between AG (MM-CGI and AGS) and caregiver burden (Montgomery scales and ZBI) was estimated initially with bivariate Pearson correlations. Multiple regression analyses were then be used to examine the ability of AG to predict caregiver burden after controlling for the following primary stressor variables: behavior problems of the care recipient (RMBPC), his or her impairments in ADLs and IADLs, and the number or hours of care provision per week. Age, income, gender and education were 
entered into the regression equation in step 1, with age and education as continuous variables, and gender and income coded into discrete variables. The primary stressor variables mentioned above were introduced into the regression analysis in the next step to determine the weight and relationship between these variables and burden. Measures of $\mathrm{AG}$ were then introduced in the final step of the regression. In order to examine the possibility that a relationship between $\mathrm{AG}$ and burden is accounted for by the strong relationship between $\mathrm{AG}$ and depression, all regression analyses were run a second time with depression entered in to the third step of the regression, and AG entered in the final step.

The final question addresses the relationship between the quality of the relationship between the caregiver and the care recipient and AG. Bivariate correlations were computed to examine the strength of the relationship between $A G$ and three areas of relationship quality, as rated by the caregiver: prior closeness, prior conflict, and satisfaction. 


\section{RESULTS}

\section{Demographics of sample}

Table 1 displays the recruitment sources for the study sample. Of the 49 participants who were adult children of the care recipients, $34.7 \%$ were recruited from caregiver support groups, $32.7 \%$ responded to university email advertisements, and the remaining $32.7 \%$ of adult child participants were recruited from advertisements in medical clinics, adult day centers, or by word of mouth. Of the 21 spousal caregivers, $71.4 \%$ were recruited from caregiver support groups, $14.3 \%$ responded to university email advertisements, and $14.3 \%$ were recruited from adult day centers of by word of mouth. Overall, the vast majority of participants were recruited from caregiver support group meetings or email advertisements.

The demographic characteristics of the participants are presented in Table 2. Consistent with other research studies (Stone, Cafferata, \& Sangal, 1987), caregivers were on average 60.53 years of age, and the majority were Caucasian $(86.2 \%)$, female $(73.8 \%)$, and primarily spouses $(26.2 \%)$ or children $(61.2 \%)$ of the care recipients. The majority were married (73.8\%), educated beyond high school $(91.3 \%)$, and about half of the sample was currently employed at the time of the interview $(47.4 \%)$. On a self-rated health item $92.4 \%$ rated their health as good, very good, or excellent and $2.5 \%$ rated it as poor. Sixty-six $(83.5 \%)$ caregivers obtained weighted scores of 0 or 1 on the 
Comorbidity Index, indicating low levels of medical comorbidity. Care recipients had a mean age of 81.65 , and were primarily female $(70 \%)$.

Table 3 summarizes the characteristics of the caregiving situation. On average, caregivers had been providing care for about 4 years, and for approximately 43 hours per week. The majority of care recipients were in moderate or moderately severe stages of dementia $(66.2 \%)$ based on the FAST, and resided at home with the caregiver (44\%). Fifteen caregivers $(18.8 \%)$ had some prior experience providing care for someone with dementia.

Descriptive statistics for the adult child caregivers, and spousal caregivers, and for the entire study sample for the key study variables are displayed in Table 4 . The adult child $(n=49)$ and spousal caregivers $(n=21)$ scores on the measures of social support, well-being, depression, burden (Montgomery Burden Inventory and Zarit Burden Interview), and anticipatory grief (Anticipatory Grief Scale, and Marwit-Meuser Caregiver Grief Inventory), were statistically similar. Additionally, the spousal and adult child caregivers' ratings of the care recipients' levels of physical impairment, behavior problems, and severity of dementia were statistically similar. Finally, the spouse and adult child caregivers did not differ significantly in levels of education, income, ethnicity, prior experience with caregiving, or amount of caregiving assistance services utilized (all p-values greater than .18). Not surprisingly, the spousal caregivers were significantly older than the adult child caregivers $\left(\mathrm{t}_{(63)}=8.54, \mathrm{p}<.001\right)$, had significantly greater levels of medical comorbidity $\left(\mathrm{t}_{(63)}=3.53, \mathrm{p}=.001\right)$, and a greater proportion of spousal caregivers were retired or not working than the adult child caregivers $\left(X_{(\mathrm{df}=2)}^{2}=11.74, p\right.$ $=.003)$. Adult child caregivers were significantly more likely to be female $\left(X_{(\mathrm{df}=1)}^{2}=\right.$ 
$11.17, p=.001)$, and have care recipients who were residing in a residential facility $\left(X^{2}\right.$ (df $=1)=5.33, p=.02$ ). Finally, spousal caregivers were spending significantly more time per week engaged in caregiving tasks $\left(\mathrm{t}_{(63)}=3.43, \mathrm{p}=.001\right)$ than the adult child caregivers.

Table 5 displays the bivariate correlations between each of the demographic characteristics with the two measures of $A G$ and the two measures of caregiver burden. Small and non-significant relationships are observed between AG and each of the demographic variables. A significant negative association exists between age and caregiver burden $(\mathrm{r}=-.34, \mathrm{p}<.01$ for $\mathrm{ZBI}, \mathrm{r}=-.22, \mathrm{p}=.05$ for Montgomery) such that younger participants reported feeling greater levels of burden than older participants. Additionally, education has a significant relationship with caregiver burden $(\mathrm{r}=.22, \mathrm{p}=$ .05 for $\mathrm{ZBI}, \mathrm{r}=.26, \mathrm{p}=.02$ for Montgomery) such that those with higher levels of education reported feeling greater levels of burden.

As a point of comparison with other studies, AG scores for the current sample are displayed in Table 6, along with available scores on the AGS and MM-CGI in other recent published studies. On average, the AGS scores are slightly higher than those in the Marwit and Meuser (2002) study, and the MM-CGI scores of the current sample are comparable to those in the Marwit and Meuser (2002) and Adams and Sanders (2004) studies.

\section{Hypothesis 1 Analysis}

In an effort to validate the construct of $A G$ in dementia caregivers, Hypothesis 1 predicted that AG would be associated with well-established correlates of caregiver 
burden. Specifically, it was hypothesized that higher levels of AG would be associated with greater symptoms of depression, less positive well-being, worse physical health, and lower levels of social support. Table 7 summarizes the bivariate correlations among these variables. Regarding the associations between these variables and caregiver burden in the current sample, AG and depression were significantly related to caregiver burden, such that higher levels of AG and depression were related to higher levels of burden.

Additionally, well-being and social support were significantly related to caregiver burden such that those with higher levels of well-being and social support tended to have lower levels of burden. However, the relationships between the two measures of burden and self-rated health and the CMI are non-significant in this sample.

As predicted, significant relationships exist between the MM-CGI and the GDS ( $\mathrm{r}$ $=.51)$ and the AGS and GDS $(r=.60)$, such that higher levels of grief are associated with higher levels of depressive symptoms. A significant relationship was also observed between each of the AG measures and Ryff's Psychological Well-being scale $(r=-.38$ for MM-CGI, and $r=-.53$ for AGS), such that higher levels of AG are associated with lower levels of well-being. Finally, significant negative relationships exist between the MMCGI and the ISEL $(r=-.40)$ and the AGS and the ISEL $(r=-.43)$, indicating that higher levels of grief are associated with lower levels of social support. The associations between $\mathrm{AG}$ and health, as measured by the CMI and the self-rated health item are nonsignificant.

To further clarify the relationship between AG and burden bivariate correlations were calculated between the two measures of burden (ZBI and Montgomery Burden Scale), and the three subscales of the MM-CGI. MM-CGI subscale A, personal sacrifice 
and burden, had the strongest relationship to both measures of caregiver burden $(\mathrm{r}=.79$ for $\mathrm{ZBI}, \mathrm{r}=.76$ for Montgomery). MM-CGI subscale $\mathrm{B}$, heartfelt sadness and longing, had the smallest, yet moderate, correlations with both burden measures $(r=.46$ for $\mathrm{ZBI}, \mathrm{r}$ $=.52$ for Montgomery), and subscale $\mathrm{C}$, worry and felt isolation had moderate to large correlations with both burden measures $(r=.63$ for $\mathrm{ZBI}, \mathrm{r}=.68$ for Montgomery). All correlations were highly significant $(p>.01)$.

\section{Hypothesis 2 Analysis}

Hypothesis 2 predicted that $\mathrm{AG}$ would be associated with characteristics of the dementia severity in the care recipients, such that higher levels of grief would be observed at later stages of the disease. Table 8 summarizes the bivariate correlations among AG and disease stage, as measured by the FAST, number of memory and behavior problems assessed using the RMBPC, and number of ADL and IADL impairments. Significant correlations were observed between AG and number of memory and behavior problems $(\mathrm{r}=.37$ for MM-CGI, and $\mathrm{r}=.29$ for AGS) such that higher levels of grief are associated with more reported problems. Additionally, significant correlations were observed between AG and the caregivers' reaction to memory and behavior problems (i.e. how much they were bothered by problem behaviors) exhibited by the care recipient $(\mathrm{r}=.55$ for MM-CGI, and $\mathrm{r}=.47$ for AGS). However, small and non-significant relationships exist between the two measures of grief with FAST disease stage and number ADL and IADL impairments.

As a follow-up, correlations were calculated to examine which subscales of RMBPC (memory, disruptive behaviors, depression) are most strongly associated with 
grief (Table 9). Results of this analysis reveal that the relationship between AG and frequency of behavior problems was strongest for depression-related problems $(r=.42$ for MM-CGI, $\mathrm{r}=.39$ for AGS, $\mathrm{p}<.01$ for both). A significant association was observed between MM-CGI scores and frequency of disruptive problem behaviors $(r=.26)$, however the relationship between frequency of memory-related behavior problems and grief was non-significant. With regard to the relationship between caregivers' reaction to behavior problems and $A G$, significant relationships were observed between $A G$ scores and reactions to depression-related problems $(r=.44$ for MM-CGI, $r=.40$ for AGS), memory-related problems ( $r=.37$ for MM-CGI, $r=.37$ for AGS), and disruptive-related behavior problems $(r=.33$ for MM-CGI).

Mean levels of AG by FAST stage are displayed in Table 10. On a descriptive level, intensity of AG on the MM-CGI appears to increase incrementally through stages 4,5 , and 6 and then drop off in stage 7. In contrast, on the AGS mean levels of AG appear to increase throughout the progression of the disease. To examine the differences in these mean levels of grief, two separate Analyses of Variance (ANOVAs) were computed using the two measures of AG (Tables 11 and 12). The results of these analyses suggest that levels of $\mathrm{AG}$ do not change significantly across disease stages.

Hypothesis 3 Analysis

Hypothesis 3 predicted that AG would be a significant independent predictor of caregiver burden across disease stages. Specifically, it was hypothesized that AG would contribute significantly to caregiver burden even after controlling for demographic characteristics of the caregiver and primary stressors including behavior problems, 
impairments in ADLs and IADLs, and the number or hours of care provision per week. To test this, four separate hierarchical linear regression analyses were conducted, using each of the two AG measures as predictor variables for each of the two caregiver burden measures as outcomes. Tables 13-16 summarize the findings from these hierarchical linear regressions used to test this hypothesis.

Table 13 summarizes the regression analysis with $\mathrm{ZBI}$ as the outcome measure, using MM-CGI as a predictor variable. The results indicate that the demographic variables entered in block 1 (age, income, gender, and education) explain a statistically significant portion of the variance in $\mathrm{ZBI}$ scores $\left(\mathrm{R}^{2}=.16\right)$. The regression coefficients for age $(\mathrm{t}=-2.14, \mathrm{p}=.04)$ and education $(\mathrm{t}=2.73, \mathrm{p}<.01)$ were significantly different from zero such that younger participants and those with higher education tended to have greater levels of burden. The addition of primary stressor variables (behavior problems, $\mathrm{ADL}$ and IADL impairments, and amount of care) in block 2 did not significantly improve the amount of variance explained in caregiver burden $\left(\Delta R^{2}=.11\right)$, nor were any of the regression coefficients for the individual variables significantly different from zero. The addition of $\mathrm{AG}$ in block 3 explained a statistically significant portion of the variance in $\mathrm{ZBI}$ scores $\left(\Delta \mathrm{R}^{2}=.34\right)$, suggesting that $\mathrm{AG}$, as measured by the MM-CGI, explained approximately $34 \%$ of the variance in caregiver burden after controlling for demographics and primary stressor variables. The final model including all variables explained approximately $62 \%$ of the variance in caregiver burden, as measured by the ZBI.

Table 14 summarizes the regression analysis with the full Montgomery Burden Inventory as the outcome measure, using the MM-CGI as the predictor variable for AG. 
In this model, the variables in blocks 1 and 2 did not explain a significant portion of the variance in burden, however the regression coefficient for education was significantly different from zero $(t=3.69, p<.01)$. The addition of $A G$ in block 3 revealed that $M M-$ CGI scores explain a statistically significant portion of the variance in caregiver burden $\left(\Delta R^{2}=.44\right)$, with the final model explaining approximately $65 \%$ of the variance in caregiver burden, as measured by the Montgomery Burden Inventory.

Table 15 summarizes the regression analysis with ZBI as the outcome measure, using AGS as the predictor variable for AG. The results indicate that the demographic variables entered in Block 1 explain a statistically significant portion of the variance in ZBI scores $\left(\mathrm{R}^{2}=.16\right)$. The regression coefficients for age $(\mathrm{t}=-2.03, \mathrm{p}=.04)$ and education $(t=2.04, p=.05)$ were significantly different from zero. As in the previous regression analysis with the ZBI, the addition of primary stressor variables did not significantly improve the amount of variance explained in caregiver burden $\left(\Delta \mathrm{R}^{2}=.11\right)$. The addition of AG in block 3 explained a statistically significant portion of the variance in $\mathrm{ZBI}$ scores $\left(\Delta \mathrm{R}^{2}=.34\right)$, suggesting that after controlling for the effects of demographics and primary stressor variables $\mathrm{AG}$, as measured by the AGS, explained approximately $34 \%$ of the variance in caregiver burden. The final model including all variables explained approximately $61 \%$ of the variance in caregiver burden, as measured by the ZBI,

Table 16 summarizes the regression analysis with the full Montgomery Burden Inventory as the outcome measure, using AGS as the predictor variable for AG. As with the previous Montgomery Burden regression model, the variables in blocks 1 and 2 did not predict a significant portion of the variance in burden, however the regression 
coefficient for education was significantly different from zero $(\mathrm{t}=2.04, \mathrm{p}=.05)$. The addition of $\mathrm{AG}$ in block 3 revealed that $\mathrm{AGS}$ scores explained a statistically significant portion of the variance in caregiver burden $\left(\Delta \mathrm{R}^{2}=.42\right)$, with the final model explaining approximately $63 \%$ of the variance in caregiver burden, as measured by the Montgomery Burden Inventory.

The above hierarchical linear regression analyses were each run a second time with depressive symptoms included as a covariate in the third block, and AG entered in the final block of the equation. This was done to test the hypothesis that $\mathrm{AG}$ would remain a significant independent predictor of caregiver burden even after controlling for the effects of depression in addition to demographic variables and primary stressors. As described above, when ZBI was used as the outcome variable measuring caregiver burden (Tables $17 \& 19$ ) demographic variables explained a significant portion of the variance in burden (approximately 16\%), and the addition of primary stressor variables did not significantly improve the amount of variance explained $\left(\Delta \mathrm{R}^{2}=.11\right)$. The addition of depression significantly increased the amount of variance explained $\left(\Delta R^{2}=.26\right)$, and depression was a significant predictor of burden, such that those with greater levels of depression were more likely to experience greater levels of burden $(t=3.49, p=.001$ for MM-CGI model; $\mathrm{t}=2.92, \mathrm{p}=.005$ for AGS model). Finally, the addition of AG in block 4 significantly increased the amount of variance explained in each model (MM-CGI $\Delta \mathrm{R}^{2}$ $=.15$, and $\mathrm{AGS} \Delta \mathrm{R}^{2}=.12$ ), meaning that the two measures of $\mathrm{AG}$ account for an additional $15 \%$ and $12 \%$ of the variance in ZBI scores after controlling for demographics, primary stressors, and depression. 
Tables 18 and 20 summarize the regression analyses in which depression was entered in the third block and the Montgomery Burden Inventory was used as the outcome measure. As described above, the variables in blocks 1 and 2 did not predict a significant amount of variance in caregiver burden. However the inclusion of depression significantly increased the amount of explained variance, with an additional $27 \%$ of the variance in burden explained $\left(\Delta \mathrm{R}^{2}=.27\right)$. In this model depression was also a significant predictor of burden, such that those with greater levels of depression were more likely to experience greater levels of burden $(t=3.18, p=.002$ for MM-CGI model; $t=2.52, p=$ .014 for AGS model). The addition of AG in block 4 significantly increased the variance explained in each model (MM-CGI $\Delta \mathrm{R}^{2}=.21$, and AGS $\Delta \mathrm{R}^{2}=.18$ ), meaning that the two measures of $\mathrm{AG}$ account for $21 \%$ and $18 \%$ of the variance in Montgomery Burden Inventory scores after controlling for demographics, primary stressors, and depression.

\section{Hypothesis 4 Analysis}

Hypothesis 4 predicted that levels of AG would be associated with characteristics of the relationship between the caregiver and the care recipient. Using single-item subjective ratings, caregivers were asked to rate their satisfaction with the current relationship, the amount of conflict and the amount of closeness in the relationship prior to the care recipient becoming ill. It was predicted that higher levels of satisfaction and closeness, and lower levels of conflict in the relationship would be significantly related to higher levels of AG. Table 21 displays the bivariate correlations between the two measures of $\mathrm{AG}$ and the three aspects of relationship quality (amount of closeness and conflict before the care recipient became ill, and current satisfaction with the 
relationship). The caregivers' satisfaction with the current relationship with the care recipient was significantly related to the scores on the AGS $(r=-.27, p=.02)$, and MMCGI $(r=-.30, p=.01)$ such that higher levels of AG were associated with lower levels of satisfaction in the relationship. The amount of conflict that caregivers rated as present in the relationship prior to the illness was significantly associated with scores on the MMCGI $(r=.27, p=.02)$ such that higher levels of grief were associated with higher levels of past conflict. The amount of closeness caregivers' felt in the relationship prior to the illness was not significantly related to any of the AG measures or subscales.

To further examine the associations between relationship quality and AG, correlations were examined between the three relationship quality ratings and the subscales of the MM-CGI. These correlations are displayed in Table 22. The caregivers satisfaction with the current relationship was also significantly related to each of the three subscales of the MM-CGI (personal sacrifice and burden $r=-.32, p<.01$; heartfelt sadness and longing $\mathrm{r}=-.27, \mathrm{p}=.02$, worry and felt isolation $\mathrm{r}=-.22, \mathrm{p}<.05$ ) such that lower levels of satisfaction were associated with higher levels of AG on all three scales. The amount of conflict in the relationship was significantly associated with the subscale scores of personal sacrifice and burden $(\mathrm{r}=.27, \mathrm{p}=.02)$ and worry and felt isolation $(\mathrm{r}=$ $.27, p=.02$ ), such that higher levels of conflict were associated with higher levels of AG. 


\section{DISCUSSION}

This study explored the nature of anticipatory grief in a sample of dementia caregivers and examined whether it contributes to our understanding of caregiver burden. Findings suggest that AG is strongly related to caregiver burden and many of the correlates of burden. Support was found for the notion that AG can significantly contribute to our current understanding of the burden experienced by dementia caregivers. Findings provide limited support for the idea that AG is related to the severity of dementia, suggesting that behavior problems exhibited by the care recipient may influence the caregiver's grief experience. Four main research questions and related hypotheses were addressed with the broad aims of describing the nature and correlates of AG in this group, and examining the relationship between AG and caregiver burden.

\section{Study Question One: Is AG related to caregiver burden and its correlates?}

Hypothesis 1 predicted that caregivers' experience of AG would be associated with caregiver burden, and several important psychological correlates of burden including depression, well-being, physical health, and social support. Support was found for this hypothesis in that caregivers feeling more burdened or distressed by the tasks of caregiving, were also experiencing greater levels of grief in reaction to the losses inherent in the caregiving situation. This finding is consistent with existing reports examining grief and burden in dementia caregivers. Marwit and Meuser $(2002,2005)$ found 
significant associations between the MM-CGI and the AGS and caregiver burden, and Walker and Pomeroy (1997) demonstrated that grief significantly predicted the amount of subjective distress reported by caregivers.

Those caregivers experiencing greater levels of grief also reported experiencing greater levels of depressive symptoms, and a less positive sense of well-being. These findings are consistent with those of Marwit and Meuser $(2002,2005)$ who also demonstrated relationships between grief, depression, and well-being. In a recent study examining predictors of grief in dementia caregivers, Ott and colleagues (2007) demonstrated that after controlling for individual, situational, and cultural factors related to the caregiving situation, scores on the Positive States of Mind scale and the CES-D each contribute a significant amount of variance to caregivers' level of AG. Overall, these findings suggest that the constructs of grief, burden, depression and well-being are all closely related and are influenced by the caregiving situation and its demands.

Hypothesis 1 was also supported by the finding that those experiencing higher levels of social support reported lower levels of AG. A consistent and strong relationship between social support and caregiver burden has been demonstrated in the literature (Clyburn et al., 2000; Coen, et al., 1997), such that those feeling more socially connected and supported report feeling less burdened by the caregiving tasks. Given the strong association between $\mathrm{AG}$ and caregiver burden, the current finding of an inverse relationship between levels of $\mathrm{AG}$ and social support is not surprising. A.gain, this finding is similar to those of Marwit and Meuser $(2002,2005)$ who found a similar relationship between $A G$ and social support. This result is also consistent with the bereavement literature which has reliably demonstrated that support from family and 
friends is one of the strongest predictors of bereavement outcomes including depression and grief symptomatology (Sanders, 1993; Stroebe, Stroebe, Abakoumkin, \& Schut, 1996; Norris \& Murrell, 1990).

Support was not found for the prediction that AG would be associated with the caregivers' health. In the current study, levels of grief were not related to a self-rated health item, nor to an objective measure of health based on the presence of chronic diseases. This could be related to the fact that the vast majority of participants in this study were in good health. The variability on these two measures of health was very low in this sample, reflecting that most participants perceived their own health as good, and had low levels of medical comorbidity. With low variability within the measures of health, it is more difficult to demonstrate covariance with other measures. The relationship between $\mathrm{AG}$ and health has been examined only in one other study, and the current finding contradicts those of Walker and Pomeroy (1997) who found that grief in caregivers significantly predicted both chronic and acute health conditions. However, in that study caregiver grief was measured using the Despair subscale of the Grief Experience Inventory, rather than a measure specifically designed to assess AG. It is possible that health is more strongly related to the experience of conventional grief, specifically to feelings of sadness and despair, than to AG. Further study is needed to clarify the nature of this relationship in other samples.

Study Question Two: Do characteristics of the disease severity influence AG?

Hypothesis 2 predicted that $\mathrm{AG}$ in caregivers would be related to disease severity in the care recipients such that higher levels of grief would be observed with increasing 
disease severity. This hypothesis was partially supported, in that behavior problems exhibited by the care recipient (one indicator of disease severity) were associated with higher levels of $A G$. Examining the subscales of the RMBPC reveals that depressionrelated behavior problems had the strongest relationship to grief, suggesting that behaviors such as tearfulness and expressing feelings of sadness, loneliness, and hopelessness may trigger more feelings of loss than other problem behaviors. Greater numbers of disruptive behavior problems reported, such as destroying property and doing things that embarrass the caregiver, were related to higher scores on the MM-CGI, suggesting that these types of behaviors may also trigger feelings of loss and grief in caregivers. Importantly, the number of memory-related behavior problems was not associated with level of grief, suggesting that behaviors such as repeating the same questions over and over and forgetting the day of the week do not trigger feelings of loss and grief.

In contrast, disease stage as measured by the FAST and other indicators of dementia severity including ADL and IADL impairments were not significantly associated with levels of AG. In the current sample, FAST stage, ADL and IADL impairments are all strongly related to one another, but not to AG or the number of behavior problems reported. Although AG scores appear to increase modestly with each progressive FAST stage (See Table 8), the difference is non-significant. Given the strong relationship between behavior problems and AG, the lack of association between disease stage and AG could be accounted for by evidence that suggests some behavior problems decrease in later stages of dementia (Haley \& Pardo, 1989). This suggests that feelings of loss and grief may be triggered by problematic behaviors exhibited by the care recipient 
rather than other indicators of dementia severity. Perhaps problem behaviors contribute to a sense of a losing the care recipient rather than their level of functional dependence or the amount of care they require.

Previous investigations of the relationship between disease severity and caregiver outcomes have also yielded inconsistent results. The current results are consistent with the findings of Lindgren and colleagues (1999) who found that the care recipient's level disease severity, as measured by the Haycox Dementia Behavior Scale, did not significantly relate to caregiver grief. However, the current finding is in contrast to those of Ott and colleagues (2007), who found significantly higher levels of AG in those caring for individuals in the moderate and severe stages of dementia as compared with those within the mild stage. Similarly, Adams and Sanders (2004) found significantly greater levels of AG in caregivers who rated their loved ones to have "late stage dementia" as compared to "middle" or "early stage dementia." These inconsistencies may be in part due to differences in the measurement of disease severity. The FAST and the Haycox Dementia Behavior Scale each assess disease severity based on changes in functional performance and ADLs. In contrast, in the Adams and Sanders (2004) study, caregivers were simply asked "How would you classify your loved one's condition?" It is possible that this more subjective method of assessing disease severity is more dependent on behavior problems exhibited by the care recipient, rather than on cognitive changes or physical limitations. For example, a caregiver caring for a loved one in the early stages of dementia may be more likely to rate the disease severity as "middle" or "late" if their loved one is exhibiting extreme behavior problems such as arguing and irritability, personality changes, or persistently engaging in potentially dangerous behaviors. This 
lends further support for the idea that behavior problems, rather than objective measurements of disease severity lead to greater levels of AG.

A recent meta-analysis integrating the findings of 228 studies examining the impact of stressors on caregiver burden and depression found that behavior problems in the care recipient have a significantly stronger relationship to both caregiver burden and depression than all other indicators of disease severity, including ADL or IADL impairments, cognitive impairments, and amount of weekly care provision (Pinquart \& Sorensen, 2005b). Although AG was not utilized as a variable of interest in that metaanalysis, given the strong associations between burden, depression, and grief, the finding that behavior problems play a larger role caregiver outcomes than do physical impairments is less surprising. This suggests that caregivers find it more difficult emotionally to tolerate behavior problems in the care recipient than physical impairments or other objective indicators of the disease severity. Moreover, the present results suggest that depressive symptoms exhibited by the care recipient, including lack of interest, tearfulness, and appearing sad, trigger feelings of grief more so than memoryrelated and disruptive behavior problems. It may be that these behaviors specifically trigger a sense of losing the person, more so than other behavior problems or changes.

Study Question Three: What is the relationship between $A G$ and caregiver burden?

Hypothesis 3 predicted that AG would be a significant independent predictor of caregiver burden, even after controlling for the effects of caregiver background characteristics, primary stressor variables, and depressive symptoms. This hypothesis was supported in that AG significantly contributed to our understanding of burden, above 
and beyond the effects of background characteristics, primary stressors, and depressive symptoms. Specifically, AG explained an additional $12-21 \%$ of the variance in burden after these other factors were considered. These results imply that the relationship between $A G$ and caregiver burden is not fully accounted for by the overlap between depression and $A G$, in that $A G$ explained variance in burden above and beyond the variance explained by depressive symptoms.

These results are consistent with those of Walker and Pomeroy (1997), who found that although being of female gender and caring for a more severely impaired loved one accounted for a significant amount of the variance in caregivers' subjective levels of distress $(26 \%)$, the addition of grief to the model significantly increased the amount of variance in distress accounted for to $40 \%$. These results provide additional evidence that AG is an important predictor of caregiver burden.

This suggests that current models of caregiver burden may be improved upon by considering the strain and burden caused by feelings of loss and grief in addition to the other psychological, physical, and social sources of strain. It is possible that the addition of AG to conceptual models of caregiver burden can help to clarify the manner by which stressors in the caregiving situation uniquely influence individual caregivers. Pearlin's (1990) stress-process model is a widely used model for conceptualizing caregiver outcomes, in which caregiver burden is conceptualized as being influenced by background characteristics of the caregiver, elements of the caregiving context, objective indicators of stress, disruptions in family, economic, and work life, and the caregivers' levels of coping and social support. Although the predictors already considered in this model are critical in understanding caregiver burden, AG seems to be a unique yet 
important addition. The emotional work related to losses of one's healthy spouse or parent, his or her personality, shared memories and plans with that person, and control and autonomy over one's own life are rarely considered, and yet these seem to be important elements contributing to the burden experienced by caregivers in this sample.

Study Question Four: How is AG influenced by characteristics of the relationship between the caregiver and the care recipient?

The association between relationship quality factors and $A G$ in caregivers had not been directly investigated prior to this study. As such, hypothesis 4 was more exploratory in nature. It was predicted that higher levels of closeness and lower levels of conflict in the premorbid relationship between the caregiver and the care recipient would be related to higher levels of AG. Additionally, it was predicted that higher levels of satisfaction with the current relationship would be related to higher levels of AG.

In contrast to the prediction, results revealed that caregivers who were more satisfied with their current relationship with the care recipient were experiencing lower levels of AG. This finding is consistent with those of Lindgren and colleagues (1999) who indirectly assessed aspects of the relationship between the caregiver and care recipient through the Grief Experience Inventory (GEI). Responses to the GEI that indicated greater levels of satisfaction with the relationship were negatively correlated with feelings of grief suggesting that greater satisfaction with the relationship resulted in fewer grief responses. Rankin and colleagues (2001) found that spousal caregivers reporting low marital satisfaction endorsed significantly more depressive symptoms than those reporting high levels of satisfaction. It is possible that dissatisfaction in the 
relationship is the result of perceived losses in the relationship, such as communication, shared activities, and future plans.

Regarding level of prior conflict in the relationship between the caregiver and the care recipient, results revealed that caregivers describing their relationships as more conflicted tended to experience greater levels of AG. It could be that those with unresolved conflict with their loved ones have greater AG because they perceive that they are losing their opportunity to resolve the conflict. Examining the subscales of the MMCGI reveals that those who reported higher levels of conflict with the care recipient experienced increased feelings of worry and felt isolation, and personal sacrifice and burden. The association between prior level of closeness in the relationship and AG was non-significant, however it is interesting to note that the relationship between the closeness rating and scores on the subscale of heartfelt longing and sadness was much larger than the other two subscales and in the direction predicted $(\mathrm{r}=.20, \mathrm{p}=.07$; See Table 20). It could be that the amount of closeness in the premorbid relationship primarily influences the traditional feelings of sadness and yearning in grief, whereas the level of conflict more strongly impacts the facets of grief related to feelings of sacrifice and social isolation. For example, an individual providing care for a family member with whom they had a highly conflicted relationship may be more likely to have strong emotional reactions in response to giving up portions of his or her time, money, and social life. On the other hand, individuals caring for a family member with whom he or she had a very close, and perhaps less conflicted relationship, may be less likely to experience caregiving as a sacrifice and more likely to experience feelings of sadness and longing for the circumstances of the past. This notion is supported by research suggesting 
that caregiving relationships characterized by expressions of love and affection lead caregivers to experience more intrinsic rewards from providing care (Archbold, Stewart, Greenlick, \& Harvath, 1990). Those without relationships characterized by expressions of emotional closeness likely experience caregiving as less gratifying and may grieve more for personal sacrifices and losses. Clearly, more work is needed to fully understand how past and current relationship factors influence $\mathrm{AG}$.

In general the results of this study suggest that $A G$ is related very strongly related caregiver burden and to many of the correlates of burden. $A G$ is also influenced by the behaviors of the care recipient, and the relationship between the caregiver and care recipient. In order to further integrate the results of the current study, additional research questions regarding the nature of $\mathrm{AG}$ in dementia caregivers will be addressed below.

\section{What does this study reveal about the nature of $A G$ in dementia caregivers?}

Based on the results of this study we were able to better describe the experience of caregiver $\mathrm{AG}$ and who experiences $\mathrm{AG}$. Caregivers dealing with behavior problems in the care recipient, specifically depression-related behavior problems, and caregivers who are more bothered by these behavior problems tend to experience higher levels of grief. However, AG seems to be unaffected by the length of time the caregiver has been providing care, the amount of time per week spent in care provision tasks, the stage of dementia, or physical limitations of the care recipient. Caregivers who are experiencing elevated levels of grief are also likely to be experiencing elevated levels of depression and burden. Additionally, grieving caregivers tend to have a lower sense of well-being, and report lower levels of social support. They are less likely to be satisfied with their 
current relationship with the care recipient, and more likely to characterize their past relationship with the care recipient with high levels of conflict.

\section{Is AG a missing component in models of caregiver burden?}

Based on the results of this study AG is clearly related to caregiver burden, but where does AG fit into the current conceptualizations of burden? Returning to Pearlin's (1990) stress-process model (Figure 1), one possibility is that AG is a secondary stressor; a primary emotion experienced by caregivers that is a causal factor to the more commonly studied reactions of stress, burden, and depression. Pearlin distinguishes two types of secondary stressors. Roles strains, which relate to disturbances caused in family, occupational, and social realms as a result of the caregiving situation, and intrapsychic strains, which relate to psychological states resulting from role conflicts and primary stressors, making the caregiver more vulnerable to negative outcomes (Pearlin, Mullan, Semple, \& Skaff, 1990). AG may be an intrapsychic strain which is triggered by primary stressors (behavior problems) and role conflicts (limited time for work or other family) being experiences as losses. If this is the case, it becomes increasingly important to understand factors that contribute to $\mathrm{AG}$, as it may serve as a mediator between stressors and strains inherent in the caregiving situation, and outcomes such as burden and depression.

Another possibility is that $\mathrm{AG}$ is a component of the larger picture characterizing caregiver outcomes. We have seen that depression, burden, and grief are all highly related constructs, and it seems likely that broadening our conceptualization of caregiver outcomes to include AG can lead to a richer, more complete, understanding of the 
caregiving experience. Boss (1999) discusses that when the care recipient is physically present but key aspects of their personality and socially relevant traits are gone, caregivers may experience "ambiguous loss," resulting in confusion regarding roles and the nature of the relationship. Losses such as communication, closeness, and shared activities with the care recipient likely accumulate as the disease progresses and yet remain largely unrecognized by society, potentially leading to feelings of confusion and isolation in caregivers. By only recognizing the burden felt in response to caregiving tasks and sacrifices made, we fail to appreciate these important aspects of the emotional experience. Feelings of powerlessness and sadness related to disruption to one's spousal or parental relationship, and fear related to the knowledge that their loved one's condition will only worsen are not well-measured by caregiver burden scales. Yet the findings from the current study suggest these feelings strongly impact a caregiver's emotional well-being.

Regardless of its exact role in caregiving outcomes, this study points to the importance of broadening current models of caregiving to include AG to gain a deeper understanding of how caregivers react to and cope with caregiving stressors. Future studies should work to further clarify how AG relates to caregiving stressors and outcomes. Does $A G$ mediate the relationship between behavioral problems in the care recipient and feelings of burden? Are the negative emotional outcomes experienced by caregivers characterized by burden, depression, and anticipatory grief? Additionally, clinicians working with caregivers should consider $A G$ as a potentially important facet of a caregiver's experience. Many participants in the current study commented that grief is rarely recognized, and that they had not previously been asked about their stress and 
sadness related to loss. By being open to discussing grief, practitioners can help caregivers feel more understood and supported. In considering $A G$ as part of a caregiver's emotional experience an important question becomes, how can we differentiate AG from other related outcomes, such as burden and depression?

How can we differentiate AG from other caregiver outcomes?

On the basis of the current findings, there appears to be great overlap between symptoms of grief, depression, and burden. Based on conceptual analysis and past research the overlap between depression and grief is not surprising, as these constructs share common features and often co-occur. However, statistical evidence for the distinction between $\mathrm{AG}$ and depression is clearer in this study than is the distinction between AG and burden. In the current study GDS scores and scores on the two AG measures are correlated moderately $(r=.51$ to .60$)$ suggesting that there is a modest degree of shared variance. This is consistent with previous literature reporting that approximately $50 \%$ of the variance in depression scores was accounted for by grief (Adams \& Sanders, 2004, Walker \& Pomeroy, 1996). Although these two affective states share many of the same expressed symptoms, they are unique in a number of key features (i.e. feelings of low self-worth not typically present in grief), their causal factors (grief being a reaction to specific losses and depression being more pervasive and susceptible to genetic vulnerability), and their responses to treatment (Marwit $\&$ Meuser, 2002). In the bereavement literature, post-death grief has been distinguished from depression in that anti-depressant medications and interpersonal psychotherapy with bereaved individuals has been shown to significantly decrease depressive symptoms 
while having minimal impact on symptoms of grief (Reynolds, Miller, Pasternak, Frank, Perel, Cornes, et al., 1999). These findings suggest that depressive symptoms reported by caregivers reflect some aspects of grief, but that the larger context of the caregivers' experience likely includes reactions to loss and grief that are unaccounted for by depressive symptoms.

There is also considerable overlap between AG and caregiver burden. The results of the current study suggest that the two constructs are closely related, with bivariate correlations being moderate to large $(\mathrm{r}=.68-.73)$. Both are negative affective reactions to aspects of the caregiving situation, and both can lead to psychological, physical and social consequences for the caregiver. However, despite their overlap there is evidence that $\mathrm{AG}$ and caregiver burden are distinct constructs, each warranting unique measurement and conceptualization. In the current study, significantly greater levels of burden were observed in younger participants and those with higher levels of education, whereas levels of AG were not significantly influenced by these factors (See Table 3). Also, the amount of time spent in care provision on a weekly basis was significantly associated with level of objective burden in caregivers $(\mathrm{r}=.32, \mathrm{p}<.01)$, but is not significantly related to AG. Finally, the subscales of the MM-CGI relate somewhat differently to the measures of burden. Not surprisingly, the personal sacrifice and burden subscale related very strongly to both measures burden, whereas the heartfelt longing and sadness and worry and felt isolation subscales related less strongly, yet significantly, to the burden measures. It seems that although some facets of AG reflect feelings of burden related the caregiving role itself, such as losses of personal freedom, sleep, and energy, other facets of $\mathrm{AG}$ seem less related to burden, such as sadness related to lost shared 
activities or future plans. Although $\mathrm{AG}$ and caregiver burden overlap they demonstrate somewhat different correlates, suggesting there is some unique variance within each that is unaccounted for by the other. As pointed out by Pinquart and Sorensen (2005b), caregiver burden, and perhaps $\mathrm{AG}$, relate to reactions that are specific to the caregiving situation, whereas depression is more global and can be influenced by factors outside the caregiving situation.

The distinction among depression, burden, and grief in caregivers has important clinical implications, in that viewing caregivers' apparent depression or burden as being at least partially related to grief over the losses they are experiencing may help practitioners to tailor their interventions more effectively toward clients' needs. Moreover, intervention studies can help to clarify the distinction between these constructs by examining the utility of grief-work with caregivers. If caregivers are helped to process their emotional reactions to experienced losses, and face the reality of and adapt to loss, will they experience less burden or fewer depressive symptoms? Addressing grief with caregivers might lead to increased feelings of burden in the short-term, but healthier adjustment during the bereavement period. It is possible that by providing support for the emotional reactions to loss, in addition to support for objective and subjective feelings of burden, an aspect of caregiver distress can be accessed and attended to that has otherwise gone unrecognized, leading to better adjustment in caregivers.

\section{Limitations and Future Directions}

This was the first study to directly assess the relationship between caregiver AG and burden while controlling for the effects of factors previously known to contribute to 
burden. The results of this study suggest that AG is strongly related to caregiver wellbeing, depression, and burden, and that $\mathrm{AG}$ contributes significantly to caregiver burden above and beyond background factors, variables related to disease severity, and depressive symptoms. However, there are several limitations that should be considered when interpreting these results. This self-selected sample was composed primarily of well-educated, female, Caucasian caregivers. Despite efforts to recruit participants from a variety of backgrounds, the current sample ( $86.2 \%$ Caucasian, $12.5 \%$ African American) falls short of approximating the diversity in Jefferson County, Kentucky (75.5\% Caucasian, 20.0\% African Americans; U.S. Census Bureau, 2006). Additionally, it is possible that individuals who volunteered to participate in this study differed from those who chose not to participate in important ways, such as being healthier, experiencing fewer depressive symptoms and less burden and grief. Future studies should expand the findings of this study to a more diverse sample of dementia caregivers. All information regarding the care recipient came from the caregivers' report. As such, the accuracy of the ratings of disease severity, physical limitations, and behavior problems is unknown. It is possible that caregiver burden and depression could influence how severely caregivers perceive the illness and any behavior problems exhibited by the care recipient. Although it would have been ideal to include objective measurements of cognitive and functional impairments in the care recipient, since the outcomes of interest in this study are tied to the caregivers' perceptions of the care recipient and the situation, the method of assessment was deemed sufficient for this study.

The current study could also have been improved by the inclusion of wellvalidated measures of relationship quality. The current measurement sought to broadly 
explore the nature of relationship factors as they related to $\mathrm{AG}$, and the individual questions were chosen in part to be generally applicable to spousal, adult-child, and other types of caregiving relationships. However, relationship quality is highly complex, and the current results suggest that more relationship-specific measurement (i.e. measures for spousal relationships vs. parent-child relationships) with well-validated relationship quality measures may better clarify the association between $A G$ and the nature of the caregiver-care recipient relationship.

Importantly, as this is a cross-sectional study the results are correlational and causal inferences should be interpreted cautiously. It remains to be seen if the associations observed in this study would generalize if examined using a longitudinal design. Future research on AG should aim to follow caregivers throughout the progression of dementia to explore how the experience changes over time. The use of the FAST as an estimate of disease severity approximates a longitudinal design in that we were able to examine levels of AG experienced by caregivers providing care at differing levels of disease severity. However, it will be important to learn how AG relates to disease severity within individuals over time. Perhaps as individuals observe their own loved one decline in physical and cognitive abilities AG fluctuates more than crosssectional measurements reveal.

The use of a longitudinal design may also help to further differentiate $A G$ from caregiver burden. Specifically, it is likely that if caregivers are followed throughout the progression of the disease, $\mathrm{AG}$ and burden may have differing courses. Examinations of caregiver burden over time have yielded inconsistent results (Schulz, et.al., 1995; Haley \& Pardo, 1989). While some studies provide support for the wear and tear hypothesis 
that the longer the caregiving is sustained the greater the decline in the caregiver's subjective well-being (Pot, Deeg, \& Van Dyck, 1997 ), other studies support the adaptation hypothesis, which suggests that caregivers adapt to the stress of caregiving over time (Gaugler, Kane, \& Newcomer, 2007). It is possible that the inclusion of AG into caregiving research can help to clarify this picture; perhaps caregivers adjust over time and feel less burdened, but feelings of grief continue to escalate as new losses are experiences and realized.

Not only is it possible that burden and AG have different courses throughout the duration of caregiving, perhaps they have different predictive values for bereavementrelated adjustment. It is possible that $A G$ and burden will be differentially influenced by the death of the care recipient. While caregivers will likely experience a reduced sense of burden following the death of the care recipient, it seems likely that feelings of grief might increase. The results of a prospective study examining changes in health outcomes prior to and after the death of the care recipients revealed that those reporting high levels of strain during their loved one's illness experienced a decrease in depressive symptoms during bereavement (Shulz et. al., 2001). Future research can work to tease apart the nature of this strain reported by caregivers, and examine the components related to feelings of burden and those related to grief. Longitudinal examination of AG throughout the duration of caregiving with follow-up assessments during bereavement may reveal a considerable amount about the true nature and utility of dementia caregiver AG.

Perhaps most importantly, future research should continue to establish construct validity for AG. Specifically, more attention should be paid to the measurement of the construct. The AGS has been used very rarely in research, and although the MM-CGI 
has been utilized in a handful of samples, it continues to be a relatively new measure that warrants further validation. Establishing $\mathrm{AG}$ as a distinct yet critically important aspect of caregiver distress should involve demonstration of convergent validity with other indicators of grief and loss, and discriminant validity from measures of burden and depression. Moreover, cut-scores should be established for these measures, which will increase their clinical utility and application. Future research should address the questions of "what constitutes high versus low levels of AG?" and "is there a healthy level of AG for caregivers that leads to better adjustment during bereavement?" Additionally, those working clinically with caregivers will be best able to tailor their interventions to a client's needs if their level of AG can be objectively assessed.

\section{Implications}

This study contributes to the existing literatures on caregiver burden and AG, and points to the importance of further consideration of grief as an important component contributing to the complexity of the caregiving experience. Until now, research on dementia caregiving has focused on outcomes of depression and burden with a lack of appreciation for the grief experienced by caregivers. These results suggest that future conceptualizations of caregiving which include $\mathrm{AG}$ will be more comprehensive, and will likely lead to more accurate predictions of caregiver outcomes. Intervention studies that include grief-work as a component of treatment may be useful in identifying mechanisms of change in reducing negative caregiver outcomes.

The current results also have implications relevant for clinical intervention with dementia caregivers. Those working with caregivers should be aware that caregivers 
who are grieving may have needs that go beyond education about the disease process and community resources aimed at reducing levels of caregiver burden. Caregivers may benefit from education about the nature of $A G$, and the provision of support and encouragement in the expression of their full range of emotions in response to the care recipient and the caregiving situation (Rando, 1986). Additionally, practitioners may be able to assist grieving caregivers in maintaining open communication with their loved one's and other family members, and recognizing how and when to say "goodbye" to their loved one (Rando, 1986; Walker \& Pomeroy, 1996). Grief-work with dementia caregivers will likely be unique with each individual, and will fluctuate over time as the multiple losses accumulate and are realized.

Among the most common intervention strategies aimed at helping dementia caregivers are support and educational groups (Biegel, Sales, \& Schulz, 1991). Although these groups offer general support and often specific information regarding the disease process and community resources, the results of a recent meta-analysis suggest that they have not consistently demonstrated usefulness in meeting the needs of caregivers (Acton \& Kang, 2001). Specifically, support groups, educational programs, and respite care interventions have all demonstrated little to no effect in reducing the burden experienced by caregivers. The authors suggest that one reason for this may be that burden is multifaceted, and so multiple interventions may need to be selected and tailored specifically to meet the needs of each caregiver, such as respite and support group participation (Acton \& Kang, 2001). Inadequate support for caregivers may result in unnecessarily high levels of distress for both the caregiver and the care recipient. Allocating time to education, discussion, and support for losses experienced as a result of 
the disease may increase the effectiveness of existing support and educational programs. Due to the ambiguous nature of grief in dementia, acknowledging the experience AG and helping caregivers to identify losses and negotiate roles and relationships may help them feel more validated and supported, thus reducing some distress and sense of isolation. In general, the needs of caregivers need to be reconceptualized to involve acknowledgement and support for losses that are being grieved. 


\section{REFERENCES}

Acton, G.J., \& Kang, J. (2001). Interventions to reduce the burden of caregiving for an adult with dementia: a meta-analysis. Research in Nursing \& Health, 24, 349-60.

Adams, K.B., \& Sanders, S. (2004). Alzheimer's caregiver differences in experience of loss, grief reactions, and depressive symptoms across stage of disease: A mixed method analysis. Dementia, 3, 195-210.

Aneshensel, C.S., Pearlin, L.I., Mullan, J.T., Zarit, S.H., \& Whitlatch, C.J. (1995). Profiles in caregiving: The unexpected career. New York: Academic Press.

Archbold, P. Stewart, B., Greenlick,M., \& Harvath, T. (1990). Mutuality and preparedness as predictors of caregiver role strain. Research in Nursing \& Health, 13, 375-384.

Ball, J.F. (1976).Widow's grief: The impact of age and mode of death. Omega: Journal of Death and Dying, 7, 303-373.

Baumgarten, M., Battista, R.N., Infante-Rivard, C., Hanley, J.A., Becker, R., \& Gauthier, S. (1992). The psychological and physical health of family members caring for an elderly person with dementia. Journal of Clinical Epidemiology, 45, 61-70.

Bedard, M., Molloy, W., Squire, L., Dubois, S., Lever, J.A., \& O’Donnell, M. (2001). The Zarit Burden Interview: A new short version and screening version. The Gerontologist, 41, 652-657. 
Biegel, D.E., Sales, E., \& Schulz, R. (1991). Family caregiving in chronic illness:

Alzheimer's disease, cancer, heart disease, mental illness, and stroke. Newbury Park, CA: Sage Publications.

Binger, C.M., Ablin, A.R., Feuerstein, R.C., Kushner, J.H., Zoger, S., \& Mikkelsen, C. (1969). Childhood leukemia: Emotional impact on patient and family. New England Journal of Medicine, 280, 414-418. .

Bozeman, M.F., Orbach, C.E., \& Sutherland, A.M. (1955). Psychological impact of cancer and its treatment: The adaptation of mothers to the threatened loss of their children through leukemia. Part 1. Cancer, 8, 1-19.

Brink, T., Yesavage, L., Lum., Heersema, P., Addey, M., \& Rose, T. (1982). Screening tests for geriatric depression. Clinical Gerontologist, 1, 37-41.

Carr, D., House, J.S., Kessler, R.C., Nesse, R.M., Sonnega, J., \& Wortman, C. (2000). Marital quality and psychosocial adjustment to widowhood among older adults: A longitudinal study. Journal of Gerontology: Social Sciences, 55B, S197-S207.

Chappell, N.L., \& Penning, M. (1996). Behavioral problems and distress among caregivers of people with dementia. Ageing and Society, 16, 57-73.

Charlson, M.E., Pompei, P., Ales, K.L., \& Mackenzie, C.R. (1987). A new method of classifying prognostic comorbidity in longitudinal studies: Development and validation. Journal of Chronic Disease, 40, 373-383.

Chodoff, P., Friedman, S.B., \& Hamburg, D.A. (1964). Stress, defenses, and coping behavior: Observations on parents of children with malignant disease. American Journal of Psychiatry, 120, 741-749. 
Clayton, P.J., Halikas, J.A., \& Maurice, W.L. (1971). The Bereavement of the widowed. Diseases of the Nervous System, 32, 597-604.

Clayton, P.J. Halikas, J.A., Maurice, W.L. \& Robins, E. (1973). Anticipatory grief and widowhood. British Journal of Psychiatry, 122, 47-51.

Clyburn, L.D., Stones, M.J., Hadjistavropoulos, T., \& Tuokko, H. (2000). Predicting caregiver burden and depression in Alzheimer's disease. Journal of Gerontology: Social Sciences, 55B, S2-S13.

Coen, R.F., Swanwick, G.R.J., \& O’Boyle, C.A., Coakley, D. (1997). Behaviour disturbance and other predictors of carer burden in Alzheimer's disease. International Journal of Geriatric Psychiatry, 12, 331-336.

Cohen, S., Mermelstein, R., Kamarck, T., \& Hoberman, H.M. (1985). Measuring the functional components of social support. In I.G. Sarason, \& B.R. Sarason (Eds.), Social Support: Theory, Research, and Applications, (71-94). Boston: Dordrecht.

Doka, K.J. (1984). Expectation of death, participation in funeral arrangements, and grief adjustment. Omega: Journal of Death and Dying, 15, 119-129.

Farran, C.J., Keane-Hagerty, E., Salloway, S., \& Kupferer, S. (1991). Finding meaning: An alternative paradigm for Alzheimer's disease family caregivers. Gerontologist, $31,483-489$.

Freud, S. (1917). Mourning and Melancholia. In Collected Papers, Vol. 4. New York: Basic Books, 1959.

Fulton, R., \& Gottesman, D.J. (1980). Anticipatory grief: a psychosocial concept reconsidered. British Journal of Psychiatry, 137, 45-54. 
Gallagher, D., Rose, J., Rivera, P., Lovett, S., \& Thompson, L.W. (1989). Prevalence of depression in family caregivers. The Gerontologist, 29, 449-456.

Gaugler, J.E., Kane, R.L., \& Newcomer, R. (2007). Resilience and transitions from dementia caregiving. Journals of Gerontology. Series B: Psychological Sciences and Social Sciences, 62B, 38-44.

George, L.K., \& Gwyther, L.P. (1986). Caregiver well-being: A multidimensional examination of family caregivers of demented adults. Gerontologist, 26, 253-259.

Gerber, I. (1975). Anticipatory grief and aged widows and widowers. Journal of Gerontology, 30, 225-229.

Glick, I.D., Weiss, R.S. \& Parkes, C.M. (1974). The first year of bereavement. Oxford, England: John Wiley \& Sons.

Gornia, Y., Hoyert, D., Lentzner, H., \& Goulding, M. (2006). Trends in causes of death among older persons in the United States. Aging Trends No. 6. Hyattsville, Maryland: National Center for Health Statistics.

Haley, W.E. (1997). The family caregiver's role in Alzheimer's disease. Neurology, 48, S25-S29.

Haley, W.E., Levine, E.G., Brown, S.L., \& Bartolucci, A.A. (1987). Stress, appraisal, coping, and social support as predictors of adaptational outcome among dementia caregivers. Psychology and Aging, 2, 323-330.

Haley, W.E., \& Pardo, K.M. (1989). Relationship of severity of dementia to caregiving stressors. Psychology and Aging, 4, 389-392.

Haley, W.E., West, C.A.C., Wadley, V.G., Ford, G.R., White, F.A., Barrett, J.J., Harrell, L.E., \& Roth, D.L. (1995). Psychological, social, and health impact of caregiving: 
A comparison of Black and White dementia family caregivers and noncaregivers. Psychology and Aging, 10, 540-552.

Hill, C.D., Thompson, L.W., \& Gallagher, D. (1988). The role of anticipatory bereavement in older women's adjustment to widowhood. The Gerontologist, 28, $792-796$.

Horowitz. M.J. (1976). Stress response syndromes. New York: Aronson.

Idler, E.L., \& Benyamini, Y. (1997). Self-rated health and physical disability in elderly survivors of a major medical event. Journals of Gerontology Series BPsychological Sciences \& Social Sciences, 51, S96-104.

Kane, R.A., \& Kane, R. A. (1981). Assessing the Elderly: A practical guide to measurement. Lexington, MA: Lexington Books.

Katz, S., Ford, A.B., Moskowitz, R.W., Jackson, B.A., \& Jaffe, M.W. (1963). Studies of illness in the aged. The index of ADL: A standardized measure of biological and psychosocial function. Journal of the American Medical Association, 185, 914919.

Kiecolt-Glaser, J.K., Dura, J.R., Speicher, C.E., Trask, O.J., \& Glaser, R. (1991). Spousal caregivers of dementia victims: Longitudinal changes in immunity and health. Psychosomatic Medicine, 53, 345-362.

Kubler-Ross, E. (1969). On death and dying. New York: Macmillan.

Lawton, M.P., \& Brody, E.M. (1969). Assessment of older people: self-maintaining and instrumental activities of daily living. The Gerontologist, 9, 15-19.

Lazaruz, R.S., \& Folkman, S. (1984). Stress, Appraisal, and Coping. New York: Springer. 
Lindemann, E. (1944). Symptomatology and management of acute grief. American Journal of Psychiatry, 101, 141-148.

Lindgren, C.L., Connelly, C.T., \& Gaspar, H.L. (1999). Grief in Spouse and Children Caregivers of Dementia Patients. Western Journal of Nursing Research, 21, 521 537.

Lundin, T. (1984). Morbidity following sudden and unexpected bereavement. British Journal of Psychiatry, 144, 84-88.

Loewenstein, D.A., \& Mogosky, B. (1999). The functional assessment of the older patient. In P. Lichtenberg (Ed.), Handbook of assessment in clinical gerontology (pp. 529-554). New York: John Wiley \& Sons, Inc.

Loos, C. \& Bowd, A. (1997). Caregivers of persons with Alzheimer's disease: Some neglected implications of the experience of personal loss and grief. Death Studies, $21,501-514$.

Marwit, S.J., \& Meuser, T.M. (2002). Development and initial validation of an inventory to measure grief in caregivers of persons with Alzheimer's disease. The Gerontologist, 42, 51-65.

Marwit, S.J., \& Meuser, T.M. (2005). Development of a short form inventory to assess grief in caregivers of dementia patients. Death Studies, 29, 191-205.

Meuser, T.M., \& Marwit, S.J. (2001). A comprehensive, stage-sensitive model of grief in dementia caregiving. The Gerontologist, 41(5), 658-670.

Montegomery, R.J., Gonyea, J.G., \& Hooyman, N.R (1985). Caregiving and the experience of subjective and objective burden. Family Relations: Journal of Applied Family \& Child Studies, 34, 19-26. 
Moore, C.A., \& Lichtenberg, P.A., (1996). Neuropsychological prediction of independent functioning in a geriatric sample: A double cross validation study. Rehabilitation Psychology, 41, 115-130.

Morris, J.C. (1993). The clinical dementia rating scale (CDR): Current version and scoring rules. Neurology, 43, 2412-2414.

Natterson, J.M., \& Knudson, A.G. (1960). Observations concerning fear of death in fatally ill children and their mothers. Psychosomatic Medicine, 22, 456-465.

Norris, F.H, \& Murrell, S.A. (1990) Social support, life events, and stress as modifiers of adjustment to bereavement by older adults. Psychology and Aging. 5, 429-436.

O'Bryant, S.L. (1990). Forewarning of a husband's death: Does it make a difference for older widows? Omega: Journal of Death and Dying, 22, 227-239.

Ott, C.H., Sanders, S., \& Kelber, S.T. (2007). Grief and personal growth experience of spouses and adult-child caregivers of individuals with Alzheimer's disease and related dementia. The Gerontologist, 47, 798-809.

Parkes, C.M. (1964). Effects of bereavement on physical and mental health-A study of medical records of widows. British Medical Journal, 2, 274-279.

Parkes, C.M. (1975). Determinants of outcome following bereavement. Omega: Journal of Death and Dying, 6, 303-323.

Pearlin, L.I., Mullan, J.T., Semple, S.J., \& Skaff, M.M. (1990). Caregiving and the stress process: An overview of concepts and their measures. The Gerontologist, 30, 583594. 
Pinquart, M., \& Sorensen, S. (2005a). Caregiving distress and psychological health of caregivers. In Kimberly V. Oxington (Ed.). Psychology of Stress (pp165-206), Hauppauge, NY: Nova Biomedical Books.

Pinquart, M., \& Sorensen, S. (2005b). Associations of Stressors and Uplifts of Caregiving with caregiver burden and depressive mood: A Meta-Analysis. Journal of Gerontology: Psychological Sciences, 58B, 112-128.

Pot, A.M., Deeg, J.H., \& Van Dyck, R. (1997). Psychological well-being of informal caregivers of elderly people with dementia: changes over time. Aging \& Mental Health, 1, 261-268.

Pruchno, R.A., \& Resch, N.L. (1989). Aberrant behaviors and Alzheimer's disease: Mental health effects on spouse caregivers. Journal of Gerontology: Social Sciences, 44, S177-S182.

Rando, T.A., (1986). A comprehensive analysis of anticipatory grief: perspectives, processes, promises, and problems. In T. Rando (Ed.), Loss and anticipatory grief (pp.1-36). New York: Lexington Books.

Rando, T.A. (2000). Anticipatory mourning: A review and critique of the literature. In T. Rando (Ed.), Clinical dimensions of anticipatory mourning: Theory and practice in working with the dying, their loved ones, and their caregivers (pp. 17-50). Champaign, Illinois: Research Press.

Rankin, E.D., Haut, M.W., \& Keefover, R.W. (2001). Current marital functioning as a mediating factor in depression among spouse caregivers in dementia. Clinical Gerontologist, 23, 27-44. 
Raveis, V.H., Siegal, K., \& Sudit, M. (1990). Psychological impact of caregiving on the caregiver: A critical review of research methodologies. In D.E. Biegel \& A. Blum (Eds.), Aging and caregiving: Theory, research, and policy (pp. 53-75). Thousand Oaks, CA: Sage Publications, Inc.

Reisberg, B. (1988). Functional Assessment Staging (FAST). Psychopharmacology Bulletin, 24, 653-659.

Reisberg, B. Ferns, S.H., Torossian, C., Kluger, A., \& Monteiro, L. (1992). Pharmacologic treatment of Alzheimer's disease: A methodologic critique based upon current knowledge of symptomatology and relevance for drug trials. International Psychogeriatric, 4, 9-42.

Reynolds, C.F., Miller, M.D., Pasternak, R.E., Frank, E., Perel, J.M., \& Cornes, C.(1999). Treatment of bereavement-related major depressive episodes in later life: A controlled study of acute and continuation treatment with nortiptylline and interpersonal psychotherapy. American Journal of Psychiatry, 156, 202-208.

Richmond, J.B., \& Waisman, H.A. (1955). Psychologic aspects of children with malignant disease. American Journal of Diseases of Children, 89, 42-47.

Ryff, C.D., Lee, Y.H., Essex, M.J., \& Schmutte, P.S. (1994). My children and me: Midlife evaluations of grown children and self. Psychology and Aging, 9, 195205.

Sachs, G.A., Shega, J.W., \& Cox-Hayley, D. (2004). Barriers to excellent end-of-life care for patients with dementia. Journal of General Internal Medicine, 19, 1057-1063.

Sanders, C.M. (1982). Effects of sudden vs. chronic illness death on bereavement outcome. Omega: Journal of Death and Dying, 13, 227-241. 
Sanders, C. M. (1993). Risk factors in bereavement outcome. In M. Stroebe, W. Stroebe, \& R. O. Hansson (Eds.). Handbook of bereavement: Theory, research and intervention (pp. 255-267). New York: Cambridge University Press.

Sanders, C.M., Mauger, P.A., \& Strong, P.N. (1985). A manual for the grief experience inventory. Blowing Rock, NC: The Center for the Study of Separation and Loss.

Sanders, S., \& Corely, C.S. (2003). Are they grieving? A qualitative analysis examining grief in caregivers of individuals with Alzheimer's disease. Social Work in Health Care, 37, 35-53.

Schulz, R., Beach, S.R., Lind, B., Martire, L.M., Zdaniuk, B., \& Hirsch, C., et al. (2001). Involvement in caregiving and adjustment to death of a spouse: Findings from the caregiver health effects study. $J A M A, 285,3123-3129$.

Schulz, R., O’Brien, A.T., Bookwala, J., \& Fleissner, K. (1995). Psychiatric and physical morbidity effects of dementia caregiving: Prevalence, correlates, and causes. Gerontologist, 35, 771-791.

Sclan, S.G., \& Reisberg, B. (1992). Functional Assessment Staging (FAST) in Alzheimer's disease: Reliability, Validity, and Ordinality. International Psychogeriatrics, 4, 55-69.

Sheikh, J. I., \& Yesavage, J. A. (1986). Geriatric Depression Scale (GDS): Recent evidence and development of a shorter version. Clinical Gerontologist, 5, $165-$ 173.

Stone, R., Cafferata, G.L., \& Sangl, J. (1987). Caregivers of the frail elderly: a national profile. Gerontologist, 27, 616-626. 
Stuckey, J.C., Neundorfer, M.M., \& Smyth, K.A. (1996). Burden and well-being: the same coin or related currency? The Gerontologist, 36, 686-693.

Stroebe, W., Stroebe, M., Abakoumkin, G., \& Schut, H. (1996). The role of loneliness and social support in adjustment to loss: A test of attachment versus stress theory. Journal of Personality and Social Psychology, 70, 1241-1249.

Teri, L., Traux, P., Logsdon, R., Uomoto, J., Zarit, S., \& Vitaliano, P.P. (1992). Assessment of Behavioral Problems in Dementia: The revised memory and behavior problems checklist. Psychology and Aging, 7, 622-631.

Teusink, P.J. \& Mahler, S. (1984). Helping families cope with Alzheimer's disease. Hospital and Community Psychiatry, 35, 152-156.

Theut, S.K., Jordan, L., Ross, L.A., \& Deutsch, S.I. (1991). Caregiver's anticipatory grief in dementia: A pilot study. International Journal of Aging and Human Development, 33, 113-118.

U.S.Census Bureau (2006). Fact Sheet: Jefferson County, Kentucky:

Retrieved, from the World Wide Web: http://factfinder.census.gov/servlet/ACSSAFFFacts?_submenuId=factsheet_0\&_sse=on

Walker, R.J., \& Pomeroy, E.C. (1997). The impact of anticipatory grief on caregivers of persons with Alzheimer's disease. Home Health Services Quarterly, 16, 55-76.

Wortman, C.B., \& Silver, R.C. (1990). Successful mastery of bereavement and widowhood: A life-course perspective. In P.B. Baltes \& M.M. Baltes (Eds.), Successful aging: Perspectives from the behavioral sciences (pp. 225-264). New York: Cambridge University Press. 
Zanetti, O., Frisoni, G.B., Bianchetti, A., Tamanza, G., Cigoli, V., \& Trabucci, M.

(1997). Depressive symptoms of Alzheimer caregivers are mainly due to personal rather than patient factors. International Journal of Geriatric Psychiatry, 13, 358367.

Zarit, S.H., Orr, N.K., \& Zarit, J.M. (1985). The hidden victims of Alzheimer's disease: Families under stress. New York: New York University Press.

Zarit, S.H., Reever, K.E., \& Bach-Peterson, J. (1980). Relatives of the impaired elderly: Correlates of feelings of burden. The Gerontologist, 20, 649-655. 
APPENDICIES 
TABLES 
Table 1

Recruitment Sources for Study Participants - no. (\%)

Recruitment Source Children $(n=49)$ Spouses $(n=21)$

Total $(n=80)$

Support Group

$17(34.7 \%)$

$15(71.4 \%)$

$35(43.8 \%)$

University Email

$16(32.7 \%)$

$3(14.3 \%)$

$22(27.5 \%)$

Advertisement

Medical Clinic

$7(14.3 \%)$

0

$9(11.3 \%)$

Adult Day Center

$7(14.3 \%)$

$2(9.5 \%)$

$9(11.3 \%)$

Word of Mouth

$2(4.1 \%)$

$1(4.8 \%)$

$5(6.1 \%)$ 
Table 2

Characteristics of Caregivers and Care recipients

Characteristic

Caregivers

Care Recipient

Age (years)

Age Range

$60.53(12.66)$

$81.65(7.68)$

$25-93$

$57-96$

Ethnicity - no. (\%)

White

$69(86.2 \%)$

Black

$10(12.5 \%)$

Asian

$1(1.2 \%)$

Gender - no. (\%)

Female

$59(73.8 \%)$

$56(70 \%)$

Male

$21(26.2 \%)$

$24(30 \%)$

Education - no. $(\%)^{\mathrm{a}}$

Less than $12^{\text {th }}$ grade

High school or GED

$2(2.5 \%)$

More than high school

$5(6.2 \%)$

$73(91.3 \%)$

Marital Status - no. (\%)

Currently married

$59(73.8 \%)$

Not married

$21(26.2 \%)$

Income - no. $(\%)^{\mathrm{b}}$

$<\$ 20,000$

$7(9.3 \%)$

$\$ 20,000-\$ 59.999$

$34(45.4 \%)$

$>\$ 60,000$

$34(45.3 \%)$

Employment Status - no. $(\%)^{\mathrm{a}}$

Full time

$27(34.6 \%)$

Part time

$10(12.8 \%)$

Retired/Not working

$41(52.6 \%)$

${ }^{\mathrm{a}}$ Data are available for 78 participants

${ }^{\mathrm{b}}$ Data are available for 75 participants 
Table 3

Characteristics of the caregiving situation

Characteristic

Relationship to care recipient

Spouse

Child

Other $^{\mathrm{a}}$

Location of care recipient

Home of caregiver

Residential Facility

Other

Time providing care (mean, SD)

Hours per week

\# months

Caregiving assistance

Support Group

In home respite

Day Center Respite

Meal services

Prior history of caregiving (\% yes)

Disease Stage

Mild dementia (FAST stages 4)

Moderate Dementia (stage 5)

Moderately Severe Dementia (stage 6)

Severe Dementia (Stage 7) no. $(\%)$

$21(26.2 \%)$

$49(61.2 \%)$

$10(12.4 \%)$

$35(44 \%)$

$28(35 \%)$

$17(21 \%)$

$42.87(52.39)$

$47.59(47.45)$

$35(44 \%)$

$9(11.2 \%)$

$17(21.2 \%)$

$3(3.8 \%)$

$15(18.8 \%)$

$19(24.8 \%)$

$21(26.2)$

$32(40 \%)$

$8(10 \%)$

a Participants categorized as "other" consisted of 4 siblings, 2 close friends, 2 romantic partners, 1 niece, and 1 granddaughter. 
Table 4

Descriptive Statistics for Key Study Variables: Mean (Standard Deviation)

Caregiver Variables

Children $(\mathrm{n}=49) \quad$ Spouses $(\mathrm{n}=21) \quad$ Total $(\mathrm{n}=80)$

Anticipatory Grief

MM-CGI

AGS

$142.02(38.52)$

$145.48(30.94)$

$74.38(12.69)$

$144.13(36.84)$

$71.84(16.16)$

$72.32(15.70)$

Caregiver Burden

Montgomery

ZBI

$63.31(12.91)$

$22.61(9.00)$

$63.24(11.69)$

$63.49(12.38)$

$20.10(7.77)$

$21.45(8.72)$

Social Support

ISEL

$19.67(3.38)$

$19.90(2.84)$

$19.86(3.23)$

Well-Being

Ryff

$79.00(11.68)$

$81.33(5.71)$

$80.09(10.03)$

Depression

GDS

$4.45(3.97)$

$3.29(2.97)$

$3.99(3.60)$

Health
CMI
$0.29(0.67)$
$1.10(1.30)$
$0.56(1.01)$
Self-Rated Health
$2.24(0.95)$
$2.55(0.83)$
$2.41(0.90)$

Variables related to care recipient

Physical Impairments
ADLs
$5.43(3.83)$
$4.52(3.83)$
$5.44(3.92)$
IADLs
$1.69(1.46)$
$1.95(1.56)$
$1.72(1.58)$

Behavior Problems

RMBPC Frequency $11.56(4.18)$

$11.00(3.16)$

$11.25(4.21)$

RMBPC Reaction 22.98 (14.26)

$18.29(10.98)$

$21.51(13.51)$

Disease Stage

FAST

$5.31(0.98)$

$5.38(0.97)$

$5.36(0.96)$ 
Table 5

Bivariate correlations among demographics and measures of $A G$ and caregiver burden

\begin{tabular}{|c|c|c|c|c|}
\hline \multirow[t]{2}{*}{ Demographics } & \multicolumn{2}{|c|}{ Anticipatory Grief } & \multicolumn{2}{|c|}{ Caregiver Burden } \\
\hline & $\underline{\mathrm{AGS}}$ & MM-CGI & $\underline{\mathrm{ZBI}}$ & Montgomery \\
\hline Age & -.18 & -.15 & $-.34 * *$ & $-.22 *$ \\
\hline Gender & .09 & .02 & .17 & .14 \\
\hline Ethnicity & -.04 & .01 & -.06 & -.003 \\
\hline Marital Status & .20 & -.07 & .10 & -.01 \\
\hline Education & -.05 & -.04 & $.22 *$ & $.26^{*}$ \\
\hline Income & -.05 & -.07 & .06 & .05 \\
\hline Employment & .02 & .08 & -.19 & -.12 \\
\hline
\end{tabular}

$* * \mathrm{p}<.01,{ }^{*} \mathrm{p}<.05$ 
Table 6

Mean (SD) Anticipatory Grief Scores in Recent Studies

\begin{tabular}{|l|c|c|}
\hline Study & AGS & MM-CGI \\
\hline Current Study & $72.32(15.70)$ & $144.13(36.84)$ \\
\hline Marwit \& Meuser (2002) & $61.21(13.59)$ & $144.0(31.6)$ \\
\hline Adams \& Sanders (2004) & -- & $\begin{array}{l}\text { Early Stage: } 149.83(33.7) \\
\text { Mid Stage: } 148.23(27.1) \\
\text { Late Stage: } 169.93(28.3)\end{array}$ \\
\hline
\end{tabular}

Note: MM-CGI = Marwit-Meuser Caregiver Grief Inventory, Range 50 -- 250

AGS = Anticipatory Grief Scale, Range 27 - 135 
Table 7

Bivariate Correlations between measures of $A G$ and correlates of burden

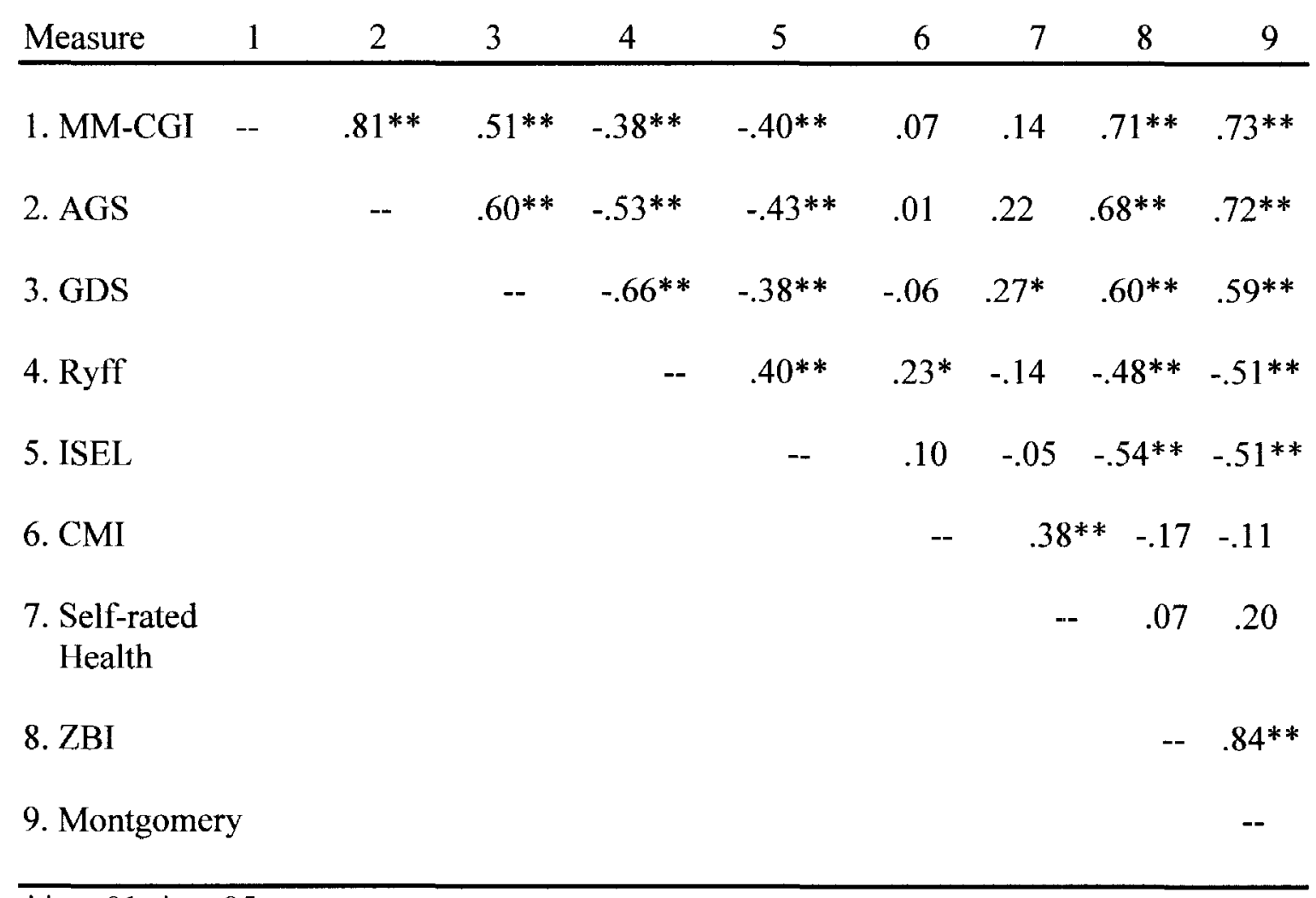

${ }^{* *} \mathrm{p}<.01,{ }^{*} \mathrm{p}<.05$

Note: MM-CGI = Marwit-Meuser Caregiver Grief Inventory; AGS = Anticipatory Grief Scale; GDS = Geriatric Depression Scale, short form; Ryff $=$ Ryff's Psychological WellBeing Scale; ISEL = Interpersonal Support Evaluation List, short form; CMI = Charslon Comorbidity Index; ZBI = Zarit Burden Interview, short form; Montgomery = Montgomery Burden Scale 
Table 8

Bivariate Correlations between AG and characteristics of disease severity

\begin{tabular}{|c|c|c|c|c|c|c|c|}
\hline Measure & 1 & 2 & 3 & 4 & 5 & 6 & 7 \\
\hline 1. $\mathrm{MM}-\mathrm{CGI}$ & -- & $.81^{* *}$ & .16 & $.37^{* *}$ & -.08 & .09 & .20 \\
\hline 2. $\mathrm{AGS}$ & & -- & .17 & $.29 * *$ & -.01 & .07 & .19 \\
\hline 3. FAST & & & - & -.02 & $.47^{* *}$ & $.71^{* *}$ & .05 \\
\hline \multicolumn{2}{|c|}{$\begin{array}{l}\text { 4. RMBPC Behavior } \\
\text { Problems }\end{array}$} & & & - & -.18 & .01 & .02 \\
\hline \multicolumn{2}{|l|}{ 5. ADLs } & & & & -- & $.48^{* *}$ & .00 \\
\hline \multicolumn{2}{|l|}{ 6. IADLs } & & & & & -- & .03 \\
\hline \multicolumn{3}{|c|}{ 7. Hours of Care } & & & & & -- \\
\hline
\end{tabular}

$* * \mathrm{p}<.01,{ }^{*} \mathrm{p}<.05$

Note: $\mathrm{MM}-\mathrm{CGI}=$ Marwit Meuser Caregiver Grief Inventory; AGS = Anticipatory Grief Scale; FAST = Functional Assessment Staging for Alzheimer's disease; RMBPC = Revised Memory and Behavior Problems checklist; ADLs = Activities in Daily Living impairments; IADLs = Instrumental Activities in Daily Living impairments 
Table 9 Bivariate correlations between AG and RMBPC subscales

\begin{tabular}{ccc}
\hline & MM-CGI & AGS \\
\hline Behavior Problems Frequency Total Score & $.37^{* *}$ & $.29^{* *}$ \\
Memory-related problem behaviors & .03 & -.07 \\
Depression-related problem behaviors & $.42^{* *}$ & $.39^{* *}$ \\
Disruptive problem behaviors & $.26^{*}$ & .18 \\
Reaction Total score & $.55^{* *}$ & $.47^{* *}$ \\
Memory-related reaction & $.37^{* *}$ & $.37^{* *}$ \\
Depression-related reaction & $.44^{* *}$ & $.40^{* *}$ \\
Disruptive-related reaction & $.33^{* *}$ & .20 \\
\hline
\end{tabular}


Table 10

Mean (SD) levels of Anticipatory Grief by FAST stage

\begin{tabular}{lll}
\hline FAST Stage & MM-CGI & AGS \\
\hline 4 Mild dementia & $132.26(35.69)$ & $68.32(13.59)$ \\
5 Moderate dementia & $143.14(31.56)$ & $71.38(12.67)$ \\
6 Moderately severe dementia & $152.97(40.99)$ & $74.69(18.58)$ \\
7 Severe dementia & $139.50(31.42)$ & $75.14(15.41)$ \\
\hline
\end{tabular}


Table 11

Analysis of Variance examining mean differences in grief scores (MM-CGI) by disease stage (FAST)

\begin{tabular}{llllll}
\hline Source & SS & df & F & partial $\eta^{2}$ & p \\
Stage & 5367.53 & 3 & 1.34 & .05 & .27 \\
Error & 101863.22 & 76 & & & \\
\hline
\end{tabular}


Table 12

Analysis of Variance examining mean differences in grief scores (AGS) by disease stage (FAST)

\begin{tabular}{rlllll}
\hline Source & SS & df & F & partial $\eta^{2}$ & $p$ \\
Stage & 558.30 & 3 & .75 & .03 & .53 \\
Error & 18662.79 & 75 & & & \\
\hline
\end{tabular}


Tables 13-16: Hierarchical Linear Regression Analyses predicting caregiver burden

Table 13

Hierarchical Linear Regression

Marwit-Meuser Caregiver Grief Inventory as measure of AG and Zarit Burden Interview as measure of caregiver burden

\begin{tabular}{|c|c|c|c|c|}
\hline Predictor Variables & $\beta$ & $\mathrm{R}^{2}$ & $\Delta \mathrm{R}^{2}$ & $\Delta \mathrm{F}$ \\
\hline Block 1 & & .16 & .16 & $3.29^{*}$ \\
\hline Age & $-.20^{*}$ & & & \\
\hline Income & .02 & & & \\
\hline Gender & .02 & & & \\
\hline Education & $.25^{* *}$ & & & \\
\hline Block 2 & & .27 & .11 & 2.37 \\
\hline Behavior problems & .05 & & & \\
\hline ADL impairments & .06 & & & \\
\hline IADL impairments & .10 & & & \\
\hline Hours of weekly care & .06 & & & \\
\hline Block 3 & & .62 & .34 & $55.38 * *$ \\
\hline $\begin{array}{l}\text { Anticipatory Grief } \\
\text { (MM-CGI) }\end{array}$ & $.66^{* *}$ & & & \\
\hline
\end{tabular}


Table 14

Hierarchical Linear Regression

Marwit-Meuser Caregiver Grief Inventory as measure of AG, and Montgomery Burden Inventory as measure of caregiver burden

\begin{tabular}{ccccc}
\hline Predictor Variables & $\beta$ & $\mathrm{R}^{2}$ & $\Delta \mathrm{R}^{2}$ & $\Delta \mathrm{F}$ \\
\hline Block 1 & -.04 & .13 & .13 & \\
Income & -.05 & & \\
Gender & .05 & & \\
Education & $.33^{* *}$ & & .09 \\
Block 2 & & .22 & \\
Behavior problems & .02 & & \\
ADL impairments & .13 & & \\
IADL impairments & .14 & & \\
Hours of weekly care & -.002 & & \\
Block 3 \\
$\begin{array}{l}\text { Anticipatory Grief } \\
\text { (MM-CGI) }\end{array}$
\end{tabular}

${ }^{*} \mathrm{p}<.01,{ }^{*} \mathrm{p}<.05$ 
Table 15

Hierarchical Linear Regression

Anticipatory Grief Scale as measure of $A G$, and Zarit Burden Interview as measure of caregiver burden

\begin{tabular}{lllll}
\hline Predictor Variables & $\beta$ & $\mathrm{R}^{2}$ & $\Delta \mathrm{R}^{2}$ & $\Delta \mathrm{F}$ \\
\hline Block 1 Age & $-.19^{*}$ & .16 & .16 & $3.29^{*}$ \\
Income & -.09 & & \\
Gender & .08 & & \\
Education & $.19^{*}$ & & .11 & \\
Block 2 & & & \\
Behavior problems & .10 & .27 & \\
ADL impairments & .03 & & \\
IADL impairments & .07 & & \\
Hours of weekly care & .11 & .34 \\
Block 3 \\
Anticipatory Grief
\end{tabular}

${ }^{* *} \mathrm{p}<, 01,{ }^{*} \mathrm{p}<.05$ 
Table 16

Hierarchical Linear Regression

Anticipatory Grief Scale as measure of AG and Montgomery Burden Inventory as measure of caregiver burden

\begin{tabular}{ccccc}
\hline Predictor Variables & $\beta$ & $\mathrm{R}^{2}$ & $\Delta \mathrm{R}^{2}$ & $\Delta \mathrm{F}$ \\
\hline Block 1 & -.03 & .13 & .13 & \\
Age & .07 & & \\
Income & .11 & & \\
Gender & $.25^{* *}$ & & \\
Education & & .22 & \\
Block 2 \\
Behavior problems \\
ADL impairments
\end{tabular}


Tables 17-20: Hierarchical Linear Regression Analyses predicting caregiver burden after controlling for depression

Table 17

Hierarchical Linear Regression

Marwit-Meuser Caregiver Grief Inventory as measure of AG, and Zarit Burden Interview as measure of caregiver burden

\begin{tabular}{|c|c|c|c|c|}
\hline Predictor Variables & $\beta$ & $\mathrm{R}^{2}$ & $\Delta \mathrm{R}^{2}$ & $\Delta \mathrm{F}$ \\
\hline$\overline{\text { Block } 1}$ & & .16 & .16 & $3.29^{*}$ \\
\hline Age & -.15 & & & \\
\hline Income & .08 & & & \\
\hline Gender & .05 & & & \\
\hline Education & $.19^{*}$ & & & \\
\hline Block 2 & & .27 & .11 & 2.37 \\
\hline Behavior problems & .03 & & & \\
\hline ADL impairments & .02 & & & \\
\hline IADL impairments & .12 & & & \\
\hline Hours of weekly care & .12 & & & \\
\hline Block 3 & & .53 & .26 & $34.66^{* *}$ \\
\hline Depression & $.32 * *$ & & & \\
\hline Block 4 & & .68 & .15 & $27.92^{* *}$ \\
\hline $\begin{array}{l}\text { Anticipatory Grief } \\
\text { (MM-CGI) }\end{array}$ & $.50^{* *}$ & & & \\
\hline
\end{tabular}

${ }^{* *} \mathrm{p}<.01,{ }^{*} \mathrm{p}<.05$ 
Table 18

Hierarchical Linear Regression

Marwit-Meuser Caregiver Grief Inventory as measure of AG, and Montgomery Burden Inventory as measure of caregiver burden

\begin{tabular}{ccccc}
\hline Predictor Variables & $\beta$ & $\mathrm{R}^{2}$ & $\Delta \mathrm{R}^{2}$ & $\Delta \mathrm{F}$ \\
\hline Block 1 Age & .004 & .13 & .13 & \\
Income & .03 & & \\
Gender & .08 & & \\
Education & $.27^{* *}$ & & \\
Block 2 \\
Behavior problems
\end{tabular}


Table 19

Hierarchical Linear Regression

Anticipatory Grief Scale as measure of AG, and Zarit Burden Interview as measure of caregiver burden

\begin{tabular}{ccccc}
\hline Predictor Variables & $\beta$ & $\mathrm{R}^{2}$ & $\Delta \mathrm{R}^{2}$ & $\Delta \mathrm{F}$ \\
\hline Block 1 Age & $-.15^{*}$ & .16 & .16 & \\
Income & .15 & & \\
Gender & .09 & & \\
Education & .15 & & \\
Block 2 & & & \\
Behavior problems & .08 & & \\
ADL impairments & -.002 & & \\
IADL impairments & .10 & & \\
Hours of weekly care & .16 & & \\
Block 3 \\
Depression 4 \\
Anticipatory Grief \\
(AGS)
\end{tabular}

${ }^{* *} \mathrm{p}<.01,{ }^{*} \mathrm{p}<.05$ 
Table 20

Hierarchical Linear Regression

Anticipatory Grief Scale as measure of $\mathrm{AG}$, and Montgomery Burden Inventory as measure of caregiver burden

\begin{tabular}{ccccc}
\hline Predictor Variables & $\beta$ & $\mathrm{R}^{2}$ & $\Delta \mathrm{R}^{2}$ & $\Delta \mathrm{F}$ \\
\hline Block 1 & .002 & .13 & .13 & \\
Income & .12 & & \\
Gender & .13 & & \\
Education & $.22^{*}$ & & \\
Block 2 \\
Behavior problems
\end{tabular}


Table 21

Bivariate Correlations between $\mathrm{AG}$ and relationship quality ratings

\begin{tabular}{|c|c|c|c|c|c|}
\hline Measure & 1 & 2 & 3 & 4 & 5 \\
\hline 1. AGS & -- & $.81 * *$ & .15 & .18 & $-.27^{*}$ \\
\hline 2. MM-CGI & & -- & .05 & $.27^{*}$ & $-.30 * *$ \\
\hline 3. Prior closeness & & & - & -.22 & -.04 \\
\hline 4. Prior conflict & & & & -- & .04 \\
\hline $\begin{array}{l}\text { 5. Current } \\
\text { Satisfaction }\end{array}$ & & & & & -- \\
\hline
\end{tabular}


Table 22

Bivariate Correlations among subscales of $A G$ and relationship quality

\begin{tabular}{|l|c|c|c|}
\hline & $\begin{array}{c}\text { Prior } \\
\text { Closeness }\end{array}$ & $\begin{array}{c}\text { Prior } \\
\text { Conflict }\end{array}$ & $\begin{array}{c}\text { Current } \\
\text { Satisfaction }\end{array}$ \\
\hline MM-CGI Total & .05 & $.27^{*}$ & $-.30^{* *}$ \\
\hline $\begin{array}{l}\text { MMCGI Personal Sacrifice and } \\
\text { Burden subscale }\end{array}$ & -.02 & $.27^{*}$ & $-.32^{* *}$ \\
\hline $\begin{array}{l}\text { MM-CGI Heartfelt Sadness and } \\
\text { Longing subscale }\end{array}$ & .20 & .18 & $-.27^{*}$ \\
\hline $\begin{array}{l}\text { MM- CGI Worry and Felt } \\
\text { Isolation subscale }\end{array}$ & -.04 & $.27^{*}$ & $-.22^{*}$ \\
\hline
\end{tabular}

${ }^{* *} \mathrm{p}<.01,{ }^{*} \mathrm{p}<.05$ 


\section{FIGURES}


Figure 1

Stress Process Model: Conceptual Model of Caregiver Stress

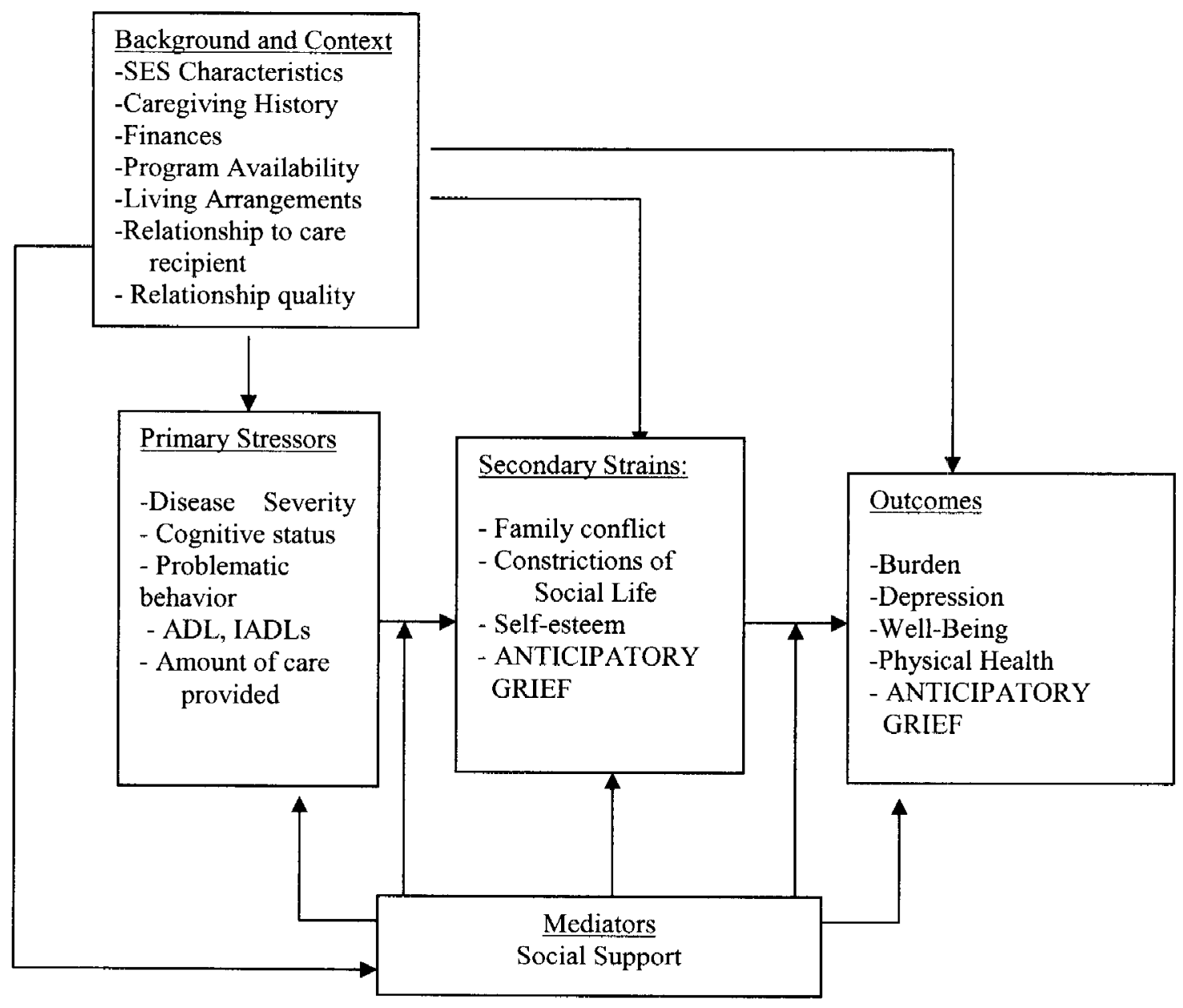

Adapted from: Pearlin, L.I., Mullan, J.T., Semple, S.J., Skaff, M.M. (1990). Caregiving and the stress process: An overview of concepts and their measures. The Gerontologist, 30, 583-594. 


\title{
CURRICULUM VITAE
}

\author{
Caitlin K. Holley \\ (Maiden name: McEntarfer)
}

\section{Contact Information:}

Boston VA Healthcare System

150 South Huntington Avenue

Boston, MA 02130

E-mail: c.holley@louisville.edu

\section{EDUCATION}

Ph.D. Clinical Psychology, December, 2009

University of Louisville, Louisville, Kentucky2009

Dissertation: Anticipatory Grief in the Context of Dementia Caregiving

M.A. Psychology, December, 2006

University of Louisville, Louisville Kentucky

B.A. Psychology, May 2003

Nazareth College of Rochester, Rochester, NY

Major: Psychology, Minor: Mathematics

GPA 3.90

\section{PUBLICATIONS}

Holley, C. K., Mast, B. T. The Effects of Widowhood and Vascular Risk Factors on LateLife Depression. (2007). American Journal of Geriatric Psychiatry, 15, 690-698.

Holley, C., Murrell, S. A., Mast, B. T. (2006). Psychosocial and Vascular Risk Factors for depression in the Elderly. American Journal of Geriatric Psychiatry, 14, 84-90.

McEntarfer, C. K., DiPirro, J. M., Page, D. A. (2005). The Effects of Gender and Aging on Pain Perception. Psi Chi Journal of Undergraduate Research, 10, 18-27. 


\section{CONFERENCE PRESENTATIONS}

Holley, C.K., Kostiwa, I.K., Rowe, S.V. Hess, L.S. The caregiver in context: The effect of patient and environmental variables on caregiver burden. Symposium to be presented at the $60^{\text {th }}$ Annual meeting of the Gerontological Society of America. San Francisco, CA (November, 2007).

Holley, C.K., Mast, B.T., Murrell, S.A. Marital Quality as a Moderator in Adjustment to Bereavement in Older Adults. Poster presented at the $59^{\text {th }}$ Annual meeting of the Gerontological Society of America. Dallas, TX (November, 2006).

Kostiwa, I, M., Holley, C.K., Azar, A.R., Mast, B.T., Meeks, S. A Taxometric Analysis of Depression In Nursing Home And Older Primary Care Samples. Poster presented at the $59^{\text {th }}$ Annual meeting of the Gerontological Society of America. Dallas, TX (November, 2006).

Vedrody, S. Holley, C.K. Mast, B.T. Frontal Systems Behavior Scale in Geriatric Primary Care Patients. Poster presented at American Psychological Association convention, New Orleans, LA (August, 2006).

Azar, A.R., Holley, C.K., Vedrody, S., Welsh, D.L., Mast, B.T. Effect of Vascular Risk and Late-Life Depression on Executive Dysfunction. Poster presented at American Psychological Association convention, New Orleans, LA (August, 2006).

McEntarfer, C. K., Mast, B. T. The Effects of Widowhood and Vascular Risk Factors on Late-Life Depression. Poster presented at the $58^{\text {th }}$ Annual meeting of the Gerontological Society of America, Orlando, Florida. (November, 2005).

McEntarfer, C. K., Mast, B. T., Murrell, S. A. The Effects of Psychosocial and Vascular Risk Factors on Depression in the Elderly. Poster presented at the American Psychological Association convention, Washington, DC. (August, 2005).

McEntarfer, C. K., DiPirro, J. M., Page, D. A. The Effects of Gender and Aging on Pain Perception. Poster presented at the Conference of the Southwestern Psychological Association., New Orleans, LA. (April, 2003).

\section{CLINICAL EXPERIENCE}

Boston Consortium in Clinical Psychology

September 2008- August 2009

- Clinical Psychology Intern

- 8 month rotation in geropsychology at the VA Boston Healthcare System Brockton Campus

- 4 month rotation at Worchester Outpatient Clinic and Brockton Neuropsychology 
Clinic Graduate Teaching Assistant

July 2007-June 2008

- Conduct intake interviews with prospective clients

- Administer and score self-report measures of clients

- Direct phone calls from clients and prospective clients

- Supervision of first-year students in interviewing and assessment skills

Interpersonal Therapy Team

June 2006- May 2008

- Graduate Student Therapist, Psychological Services Center, University of Louisville

- Conduct individual time-limited interpersonal psychotherapy with individuals experiencing interpersonal difficulties

- Supervisor: Stanley Murrell, Ph.D.

Geriatric Evaluation and Treatment Program

August 2007 - January 2008

- Attend weekly interdisciplinary meetings, involving interviewing, testing, evaluating, and consultative services to older individuals and families

Central State Hospital

August 2006-May 2007

- 800-hour practicum on geriatric and medically frail unit of inpatient psychiatric hospital

- Providing cognitive behavioral, supportive, and group therapy

- Conducting diagnostic, intellectual, and personality assessments

- Worked within a multidisciplinary team consisting of a psychologist, psychiatrist, social workers, and nurses in order to coordinate treatment for patients.

- Supervisor: Jay Irby, Ph.D.

Women's Health and Stress Team

March 2005-June 2006

- Graduate Student Therapist, Psychological Services Center, University of Louisville

- Conduct individual cognitive-behavioral psychotherapy with individuals who have experienced personal trauma and/or have been diagnosed with Post Traumatic Stress Disorder (PTSD)

- Administration of the Clinician Administered PTSD Scale and the Post-traumatic Stress Disorder Scale

- Supervisor: Tamara Newton, Ph.D.

Assessment Practicum

August 2005-July 2006

- Wedgewood Healthcare Center, Clarkesville, Indiana

- Conduct individual psychotherapy and neuropsychological and psychological assessment of nursing home residents under the supervision of a licensed clinical psychologist.

- Supervisors: Suzanne Meeks, Ph.D. and Benjamin Mast, Ph.D. 
- Psychological Services Center, University of Louisville

- Conduct semi-structured clinical interviews

- Conduct ADHD, LD, full diagnostic and intellectual functioning assessments.

- Administration of intelligence, achievement, and personality tests.

- Supervisor: Paul Bock, Ph.D., and Bernadette Walter, Ph.D.

WAIS-IV/WMS-IV Tryout Examiner April - May 2006

- Administration and scoring of WAIS-IV and WMS-IV tryout revisions to volunteers

\section{RESEARCH EXPERIENCE}

Caregiving and Relationship Experiences Study

August 2007-May 2008

- Co-investigator, University of Louisville

- Study design, recruitment of participants, conducting interviews, data entry and database management.

- Principle Investigator: Benjamin Mast, Ph.D.

Early Detection Trial of Sub-clinical Cognitive Impairment.

- Research Assistant, University of Louisville

January 2006-June 2007

- Recruitment of participants and neuropsychological assessment.

- Principle Investigator: Toni Miles, MD, Ph.D.

Geriatric Depression and Vascular Disease in Primary Care Study.

August 2004-January 2006

- Research Assistant, University of Louisville

- Responsible for data collection, neuropsychological assessment, and database management.

- Principal Investigator: Benjamin Mast, Ph.D.

Planning, Reasoning, and Everyday Problem Solving Study

April 2004-May 2005

- Research Assistant, University of Rochester, Department of Psychiatry

- Recruitment of participants,administering structured interviews to older adults to investigate their preparation for future care needs, administration of cognitive tests, database management, attending and presenting at a weekly administrative and research evaluation meeting.

- Principal Investigator: Silva Sörensen, Ph.D.

Research Fellowship

June 2002-July 2002

- Buffalo State College, Department of Psychology, Buffalo, New York.

- NIMH funded Mental Health Issues in Applied Experimental Life-Span Developmental Psychology (R25) Education Project.

- Experimental Developmental Research Methods course 
- Applied research rotations in area agencies, laboratories and hospitals

- Faculty Mentor: Jean DiPirro, Ph.D.

\section{TEACHING EXPERIENCE}

Guest Lecturer, Alzheimer's Disease and the Self, University of Louisville, Louisville Kentucky. "Grief and Anticipatory Grief in Dementia", April, 2007.

Instructor, Introduction to Psychology, University of Louisville, Louisville, Kentucky. Summer Term III, 2006.

Peer Tutor, Nazareth College of Rochester, Rochester, New York, 2002- 2003. Tutored students in Statistics, Advanced Research Methods, and Logic and Inquiry.

\section{HONORS AND AWARDS}

- Award for Excellence in Research by a Student Member, American Psychological Association Division 12, II Society of Clinical Geropsychology, 2006

- American Psychological Association Student Travel Award, 2005

- University Fellowship, Graduate School, University of Louisville, 2004-2006

- Student Service Award, Clinical Psychology Department, University of Louisville, 2005

\section{PROFESSIONAL SERVICE}

Student Representative to the Clinical Faculty, Department of Psychological and Brain Sciences, University of Louisville, January 2005-Present

Student Representative to the Society of Clinical Geropsychology, American Psychological Association, August 2006-Present

Student Representative for applicants to the doctoral program, Department of Psychological and Brain Sciences, University of Louisville, 2005.

\section{VOLUNTEER EXPERIENCE}

Highlands Community Ministries Adult Day Health Center February 2007-Present

\section{PROFESSIONAL MEMBERSHIPS}

American Psychological Association

Div. 20-Adult Development and Aging

Div. 12-2- Clinical Geropsychology

American Psychological Association of Graduate Students

Gerontological Society of America, student member 